\title{
Through The LOOKING Glass: MEDIATOR CONCEPTIONS OF Philosophy, Process AND POWER
}

\author{
COLLEEN M. HANYCZ
}

While a number of civil reforms using mediation have emerged across Canada in recent years, of particular interest is the Ontario Mandatory Mediation Program that was first piloted in 1999, deemed successful and then made a permanent feature of the Rules of Civil Procedure in 2001. This article suggests that before we can evaluate the oufcomes of mandaton mediation. we must first look more closely at the process being implemented by the mediators in this context. With that in mind, this article considers the ways in which the mediators themselves perceive of the mediation process. It reports on a qualitative stindy that examined the nature of mediator views on the topics of, inter alin, setiement orientation and mediator power. This article advances the claim that mediator power is, in fact, far greater than that held by the disputants or their advocates. This article suggests that this power, in the context of a mandatory mediation scheme, creates mediator selfinterest in achieving high rates of settlement, regardless of whether or not sellement is in the best interests of the disputants in every situation.
Au Canada. bon nombre de réformes civiles ont vu le jour au cours des dernières années, mais Mandatory Medialion Program de l'Ontario est particulietrement intéressant. Fn fait, c est en 1999 qu'il a été mis à l'essai pour la première fois. Jugé enièrement satisfaisant, il a été intégré aux Règles de procédure civile en 2001. L article suggère qu'avam de pouvoir évaluer les ressultats de la mediation nous devrions examiner de plus près le processus adopté par les médiateurs dans ce contexte. Cet article examine les différentes perceptions des médiateurs à l'égard du processus de médiation. L 'auteur fait référence à une éfude qualitative qui examinait les points de vue des médiateurs à l'égard de, notammen. la direction du règlement et le pouvoir du mediatewr. En outre, cet article suggère que te pouvoir du mediateur est de beancoup supericur au pouvoir des personnes impliquées ou de leurs dejensuurs. II suggère aussi que ce pouvoir. dans le contexte d'un plan de médiation mandataire, crée un intérèt personnel de la part du mediateur qui chercherait à atteindre des règlements élevés sans tenir compte du meilleur intérèt des personnes impliquées.

\section{TABLE OF CONTENTS}

I. INTRODUCTION $\ldots \ldots \ldots \ldots \ldots \ldots \ldots \ldots \ldots \ldots \ldots \ldots \ldots \ldots \ldots$

II. THE CONTEXT OF THE STUDY: THE ONTARIO MANDATORY

MEDIATION PROGRAM (OMMP) . .................. 823

A. HISTORY OF MANDATORY MEDIATION IN ONTARIO . . . . . . . 823

B. RESEARCH FINDINGS ..................... 824

C. THE ONTARIO MANDATORY MEDIATION PROGRAM

AS FIELD SITE . . . . . . . . . . . . . . . . . . . . . . . 825

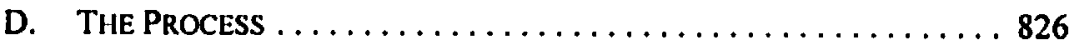

E. FINDINGS OF THE INDEPENDENT EVALUATION $\ldots \ldots \ldots \ldots \ldots \ldots 828$

III. THE DESIGN OF THE STUDY: PHENOMENOGRAPIIY

AS GROUNDED THEORY . . . . . . . . . . . . . . . . . . . . . . . . . 829

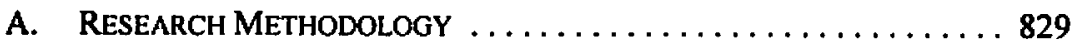

B. PHENOMENOGRAPHY $\ldots \ldots \ldots \ldots \ldots \ldots \ldots \ldots \ldots \ldots . .630$

C. APPLICATION OF PHENOMENOGRAPHY TO THIS STUDY $\ldots \ldots \ldots 832$

D. SElection Of THE StUdy Site AND THE PARTICIPANTS $\ldots \ldots \ldots 832$

E. THE INTERVIEWS $\ldots \ldots \ldots \ldots \ldots \ldots \ldots \ldots \ldots \ldots \ldots \ldots, 833$

F. Data Coll.ection and Analysis $\ldots \ldots \ldots \ldots \ldots \ldots \ldots, 835$ 
IV. FINDINGS I: MEDIATORS' CONCEPTIONS OF MEdIATION ......... 836

A. CONCEPTIONS OF THREE ElEMENTS OF MEDIATION .........836

B. CATEgorical Theories of MEdiation $\ldots \ldots \ldots \ldots \ldots \ldots .858$

V. FINDINGS II: MEDIATORS' CONCEPTIONS OF POWER IN MEDIATION . . . . 864

A. MEDIATOR CONCEPTIONS OF MEDIATOR POWER IN MEDIATION ... 864

B. RELATION OF CONCEPTIONS OF POWER TO CATEGORICAL

THEORIES OF MEDIATION . . . . . . . . . . . . . . . 876

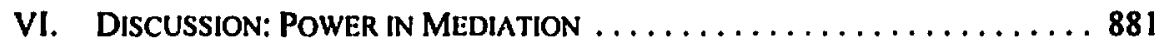

\section{INTRODUCTION}

In Ontario, and to varying degrees across the country and beyond, mediation has become an unwelcome guest at the banquet table of traditional litigation. In faimess, this guest was not uninvited as bar associations and rules committees across Canada have acknowledged the added benefit of including mediation in the growing regime of civil case management. And, admittedly, these same bar associations and rules committees have advocated for the statutory reforms that have brought mediation, both compulsory and voluntary, to the table.

However, it remains a strained relationship between the traditional parent and the rather unconventional child. Within our civil justice systems, mediation continues to carry a large degree of uncertainty. There are as many definitions of "mediation" as there are mediators, and such an unfortunate lack of clarity surrounding this process has resulted in a situation where the central stakeholders and participants in our civil justice model do not know what is going on behind mediation's closed doors. We have witnessed some scholarly inquiry into the outcomes of this process, and we have been reassured that whatever is going on is leading to better results, where "better" can be defined as faster and cheaper.' Unfortunately, claims surrounding the necessity of confidentiality and privacy have prevented any meaningful analysis of the quality of those results and we have, as a scholarly community, avoided studying with any coherence the key architects of those results, the mediators themselves.

Of greater concern should be the fact that the majority of mediation research to date has been of the input-output variety, with little meaningful research on the process itself, beyond its immediate results. While it may be trite to note that, in any system, process is the most significant factor shaping the nature and quality of outcomes, our field has not been especially rigorous in examining the mediation process in an empirical way. Before any understanding of outcome can be gained, we need to look more closely at the frameworks and practices of the mediation process. This article takes one step in that direction. It reports upon a study that focuses on the mediation process in the context of Ontario's Mandatory Mediation Program.

How do we begin to look at process systematically, when there exists such a wide variety of both internal and external variables that impact directly upon the model of mediation that is delivered? The findings reported in this article consider two interconnected variables central to the shape of the mediation process: the mediator's power and the mediator's settlement orientation. It asks two key questions that are fundamental to an examination of 
the mediation process: (1) Are mediators operating in the Ontario Mandatory Mediation Program particularly oriented towards settlement?; and, (2) What is the nature of the power that these mediators harness and how do they utilize that power, if at all, to achieve their goals? To be clear, there is no implied suggestion here that settlement-orientation is necessarily a bad thing; in fact, settlement is often in the best interest of the parties to a dispute. But, not always. One of the chief criticisms leveled at the Ontario model has been its timing; ${ }^{2}$ with many participants, parties and counsel, arguing that mediation comes too early in the process, usually before the discovery stage.

This claim is especially resonant in the context of personal injury litigation where the full extent of the injuries may not have crystallized at the mediation stage. Given that these cases compose the single greatest grouping of case managed actions, it questions whether the impact of the settlement-orientation of our rostered mediators might not be significant. Could a certain threat to disputants' interests not be posed by a mediator with either a subconscious or hidden settlement-orientation in those cases where settlement at the early stage of mediation may not correspond with the best interests of the disputants themselves? And what about those cases, timing of mediation aside, that simply may be better served by the full treatment of public adjudication? Given these contexts, I felt justified in beginning my project with the assumption that settlement through early mediation may not correspond with the best interests of the disputants in every situation.

Of late, fieldwork has begun to emerge that proposes and/or tests theories on the topic of mediator orientations. ${ }^{3}$ The emerging results suggest that the perceptions and views of mediators have considerable impact on the trajectory of the dispute at the heart of their process. ${ }^{4}$ In one study, researchers argued that mediators favour particular outcomes in a given dispute and, to that end, direct the process accordingly. ${ }^{5}$ In earlier work, Sara Cobb and Janet Rifken have argued that a mediator's orientation to neutrality directly shapes the mediation process. In 1991, they proposed, along with Jonathan Millen, that the ways in which mediators see power has a similarly important impact on the process and, necessarily, outcomes. In the context of international conflict, Saadia Touval and William Zartman ${ }^{6}$ adopt a "rational actor" approach to conclude that the motives of international mediators to engage

2 Julie Macfarlane, "Culture Change? A Tale of Two Cities and Mandatory Court-Connected Mediation" [2002] J. Disp. Resol. 241.

- See e.g. Margaret S. Herrman, Nancy L. Hollett, Dawn Goettler Eaker \& Jerry Gale, "Medialor Reflections on Practice: Connecting Select Demographics and Preferred Orientations" (2003) 20 Conf. Resol. Q. 403; Scott Jacobs \& Mark Aakhus, "What Mediators do with Words: Implementing Three Models of Rational Discussion in Dispute Mediation" (2002) 20 Conf. Resoi. Q. 177: Michael D. Lang \& Alison Taylor, The Making of a Mediator: Developing Arisin' in Practice. (San Francisco: JosseyBass, 2000): Deborah M. Kolb. When Talk Works: Profiles of Mediators (San Francisco: Jossey-Bass, 1994).

4 Janet Rifkin, Jonathan Millen \& Sara Cobb, "Toward a New Discourse for Mediation: A Critique of Neutrality" (1991) 9 Mediation Quarterly 151: Howard H. Irving \& Michael Benjamin, Family. Mediation: Contemporan' Issues (Thousand Oaks: Sage Publications, 1995); Tricia S. Jones. "Emotional Communication in Conflict: Essence and Impact" in William F. Ladic \& Paul F: Nelson. eds., The Langwage of Conflict and Resolution (Thousand Oaks: Sage Publications, 2001) 81

5 David Greatbach \& Robert Dingwall, "Selective Facilitation: Some Preliminary Observations on a Strategy Used by divorce Mediators" (1989) 23 Law \& Soc'y. Rev. 613

- Saadia Touval \& I. William Zartman, "Mediation in International Conflicts" in Kenneth Kressel \& Dean G. Pruit, eds., Mediation Research: The Process and Effectiveness of Third-Parn Intervention (San Francisco: Jossey-Bass, 1989) 115. 
in mediation go beyond humanitarian objectives of reducing global conflict into distinctly self-interested goals of settlement and achieving closer relations with one or both of the disputing parties. While this latter study contributed to the understanding of mediators as self-interested, its methodology of historical case study prevented the most central aspect of the analysis of mediator self-interest: input from the mediators.

To clarify, this study is not about participant satisfaction. It does not suggest that certain mediator behaviour leads to happy or unhappy disputants; rather, it proposes that the ways in which mediators view mediation can be organized into categorical frameworks. By identifying patterns in mediator perceptions about mediation and, in particular, about power and settlement, we can begin to view the process of mediation through a unique and critical lens that provides a view quite distinct from that of the more common input-output studies focused on user satisfaction.

There are various approaches to an empirical consideration of the mediation process, each bringing its own set of strengths and weaknesses. While observation of the process is arguably ideal for documenting and establishing exactly what happens in mediation, I am more intrigued about the perceptions of the mediators surrounding these issues of orientation and power. I was especially curious to identifying any emergent patterns in the data that might lead to categorizing the ways in which mediators view mediation. As is discussed at greater length below, I adopted the grounded theory method of phenomenography to generate data surrounding the views and perceptions that a group of mediators has on the issues of mediator power and mediator orientation to settlement. In particular, a random sampling of rostered mediators participated in semi-structured interviews through which their views were elicited on philosophy, process and power as they relate to mandatory mediation.

What emerged from the data collected through these interviews, while most certainly only exploratory and preliminary in its scope, suggests a number of groupings of mediator orientations, specifically within the context of a mandatory mediation scheme, which may have implications for the process widely adopted in our compulsory model. This study is intentionally limited in its application; it does not suggest mediator orientations and perceptions that apply to mediators universally. However, there is nothing so particular about Ontario's experiment with mandatory mediation that would preclude the application of these findings to other mandatory models.

By practice direction dated 22 November 2004, Regional Senior Justice (Toronto) W. Winkler and Chief Justice H. Smith of Ontario's Superior Court of Justice have dramatically altered the application of case management and mandatory mediation in Toronto. Effective 31 December 2004, a three-year pilot project was implemented that brings with it significant changes to the scope of case management in Toronto and, consequently, modifies the role of mandatory mediation in this city. Among other changes, r. 24.1 governing mandatory mediation will be amended during this pilot project so that, rather than being compelled to mediate within 90 days of the filing of the first defence, parties will be expected to conduct mediation "at the earliest stage in the proceeding at which it is likely to be effective, and in 
any event, no later than 90 days after action is set down for trial by any party."' The court noted its concern with serious delays in the civil justice system in Toronto, highlighting what it finds to be unacceptably long and growing waiting times for interlocutory motions and trials. Also expressed in this practice direction was the related concern with the rising costs resulting from the increasing number of formal steps and appearances that must be undertaken.

While this shift in policy may be more directly related to factors external to what occurs in the mediation room, there is little doubt that the micromanagement of the process at the hands of the mediators is of continuing concern to all stakeholders in this process. And so, we begin our examination of this system through one of the most important lenses available.

\section{THE CONTEXT OF THE Study: \\ The ONTARIo Mandatory Mfdiation Program (THE OMMP)}

\section{A. History OF MANDATORY MEDIATION IN ONTARIO}

In 1994, Ontario established its Civil Justice Review (the Review) that was structured as a collaborative initiative of the Ontario Court of Justice (General Division) and the Ministry of the Attorney General. The Review was established to respond to public complaints that our civil justice system was inaccessible for a variety of reasons. As it was the Review that ultimately led to the implementation of mandatory mediation in Ontario, it is noteworthy to consider the its stated mandate: "to develop an overall strategy for the civil justice system in an effort to provide a speedier, more streamlined and more efficient structure which will maximize the ulilisation of public resources allocated to civil justice."

From the outset, there was a clear mandate respecting the goals of this particular courtconnected mediation program. It was to be an answer to the costly, time-consuming and inefficient backlogs of traditional adjudication in this province, and at no time did anyone talk about achieving those objectives of mediation gathered loosely under the categories of "relational" and "transformative." This was to be about improved judicial efficiency, plain and simple. While debate has continued surrounding other objectives of this program some noting its role in enabling better access to justice for disputants who are ill equipped for the costs and delay of traditional litigation - the guiding principles of the sponsoring institution are explicit. It is these very principles that have, in my view, served to create and nourish within the program's mediators a strong orientation to settlement, regardless of the case or context.

In January 1999, r. 24.1 was introduced as a pilot project; a subset of Ontario's Rules of Civil Procedure mandating early mediation for all non-family, civil case-managed cases filed in the Ontario Superior Court of Justice in Ottawa and Toronto, Ontario. This pilot project was to continue until 4 July 2001, a 23-month period during which r. 24.1 would be

, Superior Coun of Justice, Toronto Region, "Practice Direction - Backlog Reduction/Best Practices Initiative" (Toronto: 22 November 2004) at 4.

* Ontario Civil Justice Review, First Report of the Civil Jusfice Review (Toronto: Ontario Civil Justice Review, 1995) at 3-4; Ontario Civil Justice Review, Supplemental Report and Final Report of the Civil Justice Review (Toronto: Ontario Civil Justice Review, 1996) at 2 [emphasis added]. 
evaluated on four enumerated grounds: Does the rule improve the pace of litigation? Does it reduce costs to the participants? Does it improve the quality of disposition outcomes? Does it improve the operation of the mediation and litigation processes?

In March 2001, the final report of the independent evaluator (the Hann Report) was filed with the Civil Rules Committee demonstrating the increased case management efficiency that followed the implementation of r. 24.1.9 As a result of this evaluation, and arguably other factors, the test of r. 24.1 was deemed a success and it has now been proclaimed into force as a permanent part of the Rules of Civil Procedure. In addition to Ottawa and Toronto, the OMMP has now been expanded to Windsor, Ontario with reputed plans to eventually govern all non-family civil disputes brought across Ontario in the Superior Court. It is hard to assess the global impact of the recent events in the Toronto Region on these rollout plans; suffice to say that it may be the unique characteristics of the Toronto context that have generated such increased burdens on judicial resources.

Therefore, both the original objectives and the evaluation of the program emphasized settlement as the key to success, illustrated through reductions in cost and delay. What is notably absent from this framework of success is the recognition that some cases may be better served by traditional adjudication, and that to settle these cases would actually demonstrate a failure of the system to assess stakeholder interests on a case-by-case basis. Even those cases that should ultimately be resolved through negotiated settlement may not be ready for that resolution, given the early timing of mediation in Ontario.

Within ten days of the conclusion of each mediation conducted through the OMMP, mediators must file with the Local Mediation Coordinator a Medjator's Report. If a mediator was left with any lingering question surrounding the aims of the program, the report itself is certain to clarify the institutional goals. After recording the style of cause and the mediator's name, the form requests details only of the amount of time spent in mediation and whether a settlement was achieved. This report does not invite any discussion that might measure a mediation in some manner other than its settlement outcome.

\section{B. RESEARCH FINDINGS}

While there is a growing body of empirical research conducted on American mediation programs, ${ }^{10}$ the OMMP has had little attention from researchers. The Hann Report was based upon quantitative analysis of survey data completed by mediators, disputants and lawyers, detailing settlement rates, associated costs and time consumption related to the pilot project. More recently, Julie Macfarlane conducted qualitative research into the question of the

Hann, supra note 1.

Sec e.g. J. Shack, "Saves What? A Survey of Pace, Cost and Satisfaclion Studies of Court-Related Mediation Programs" (l'aper presented to the American Bar Association Mini-Conference on Court ADR, Seattlc, Washington, 4 April 2002) (unpublished]; Bobbi McAdoo, "A Report to the Minnesota Supreme Court: The Impact of Rule 114 on Civil Litigation Practice in Minnesota" (2002) 25 Hamline L. Rev, 401; Roselle L. Wissler, "Court-Connected Mediation in General Civil Cases: What We Know from Empirical Research" (2002) 17 Ohio St. J. Disp. Resol. 641; Thomas A. Kochan, Brenda A. Lautsch \& Corinne Bendersky, "An Evaluation of the Massachusetts Commission Against Discrimination Alternative Dispute Resolution Program" (2000) 5 Harv. Negot. L. Rev. 233. 
impact that Ontario's mandatory mediation experiment has had, or not had, upon the "culture" of commercial litigators in Toronto and Ottawa who act as advocates for their disputing clients in this model." Macfarlane's findings go much further in answering questions surrounding user satisfaction and assimilated philosophies of stakeholders in this scheme. However, there continues to be a striking gap in the literature, as we have failed to consider any qualitative analysis of mediators' perspectives in this program.

Originally, this study was intended to be an ethnographic investigation of the mediator culture shared by mediators associated with the OMMP. That approach was abandoned following a recognition that, while the roster does create a "grouping" of professional mediators, there is in fact very little intra-group communication or involvement. That concern was confirmed by a number of the respondents who participated in this study and who noted the isolated nature of their practices. An absence of contact between group members depleted the legitimacy of taking an ethnographic approach to this study. I suggest that the cultural ties amongst members of a cultural group are what give meaning to an ethnographic inquiry and its attempts to elicit patterns of behaviour and philosophy. That foundation simply does not exist as part of the OMMP. I discovered that any connections among members of the roster were coincidental to, not resultant from, membership on the roster.

Given a continued interest in the context shared by mediators working within the OMMP, this inquiry shifted into one that is phenomenographic in framework. Instead of drawing conclusions about the nature of the group's behaviour and attitudes resulting from membership in the OMMP roster, this work focuses on the way in which members of this group, as associated with a court-connected mediation program, conceptualize the process of mediation and the role of power.

\section{Tue Ontario Mandatory Mediation Progkam as Fitid Site:}

The OMMP is central to this study in many ways. First, it is the link that joins all of the respondents in this study and, as such, provides a common context. Additionally, the OMMP provides a platform for the mediation sessions themselves. Mediators on the roster are either chosen by disputants within 30 days of the filing of the first defence in the action, or they are randomly assigned by the Local Mediation Coordinator in the case of litigants who neglect to "select" a mediator within that one month period. While a background in law is not required for acceptance onto the roster, applicants must demonstrate a working knowledge of the Rules of Civil Procedure, specifically, and a familiarity with the civil litigation process more generally.'2

While the mediators hail from a variety of backgrounds in terms of formal education, mediation training and experience, they participate in a shared application of the mandatory mediation process in Ontario as it pertains to civil disputes. In choosing to locate this study within the Toronto roster of mediators operating under the auspices of the OMMP, I was of

11 Macfarlane, supra note 2.

1: See "Local Mediation Commiltee Guidelines for Selecting Mediators - Ontario Mandatory Mediation Program." online: Ontario Mandatory Mediation Program <www.attorncygeneral.jus.gov.on.ca' english/courts/manmed/guidelines.asp>. 
the view that the common platform provided by this program, and the standardized process for the selection of mediators for its roster, would serve to reduce some of the challenges inherent in discussing "mediation," a label affixed to such a wide variety of processes. Their common practice as roster mediators operating within a set mandatory program would hopefully reduce the definitional challenges likely to pose a problem had the respondents been selected with no commonality amongst their practices.

\section{Tile, Process ${ }^{13}$}

While the OMMP began with programs centred in Ottawa and Toronto, it has been expanded to include Superior Court actions commenced in Windsor. Each of these locations maintains a separate roster of mediators, its own Local Mediation Committee and its own Coordinator to administer the program. The room for variation among these centres is limited, given the common application of r. 24.I of Ontario's Rules of Civil Procedure and its outlining of the obligations and responsibilities of those participating in the program. As this study is based on participant mediators who sit on the Toronto roster, the findings are technically restricted to that center. That said, there is nothing to suggest that these results are not applicable across the program.

\section{THE LOCAl MEDiATION COMMITTEeS AND THE MEDiAtoR ROSTER}

Rule 24.1 establishes volunteer Local Mediation Committees in each of the included jurisdictions. Under r. 24.1, the Local Mediation Committee is required to maintain a roster of mediators to participate in mediations falling under the Rule. Mediators are invited to apply to the Local Mediation Committee for acceptance onto the roster, and such acceptance will be based on the following criteria:
(1) experience as mediator;
(2) training in mediation;
(3) educational background;
(4) familiarity with the civil justice system; and
(5) references.

In terms of conduct, mediators who apply to sit on the roster for a given jurisdiction agree to be governed by the Canadian Bar Association - Ontario's (CBAO) Model Code of Conduct for Mediators ${ }^{14}$ in its entirety, save for the fees to be charged by the mediators that is governed by the Regulation's enacted pursuant to r. 24.1. In addition to the Model Code, mediators operating on the roster of the OMMP agree to a number of other conduct

1" The detailed information respecting the OMMP process has been compiled from a variety of sources available to the public, including: "Local Mediation Committec Guidelines for Sclecting Mediators," ibid: Local Mediation Committee, "OMMP - Mediator Orientation Materials" (1999); OMMP, "Ontario Mandatory Mediation Program Communique for Roster Mediators" (various editions, since June 2000).

1t Canadian Bar Association - Ontario ADR Scction, Model Code of Conduct for Mediators, online: Ontario, Ministry of the Attomey General <innw. attorneygeneral.jus.gov. on.ca/english/courts/manmed/ codeofconduct.asp> [Model Code]. 
requirements including participating in continuing legal education, ensuring they are competent to render mediation services, encouraging faimess in the mediation process and conducting themselves in a manner that will foster public understanding of and confidence in the OMMP process.

The CBAO's Model Code contains terms that, while common to a variety of similar codes of conduct throughout North America in mandatory mediation programs, remain similarly ambiguous in their meanings. For example, the Model Code endorses the principles of party self-determination and mediator impartiality, yet neither of these concepts is defined in a way that would leave a mediator clear as to her expected conduct. And the way in which that practice may depart from the written Model Code is another matter altogether.

Under the section on party self-determination, the Model Code requires that parties have a right to make non-coerced decisions respecting the outcomes of their disputes and prohibits mediators from giving legal advice. ${ }^{16}$ Undeniably, a significant amount of the mediations being conducted today under the OMMP include coercive practises by mediators who regularly provide assertive legal advice. I raise this not to introduce the topic of mediator competence, but to underline the ambiguity respecting the mediation process that is evident even in the central documents that govern this program. I submit that Ontario's experimentation with court-connected mediation is not the first to suffer such internal uncertainty and inconsistency between theory and practice. It is one of the aims of this study to begin to understand the way in which the mediators themselves understand what it is that they are doing within this program and otherwise.

\section{THE MIEDIATION SESSIONS}

The Ontario Rules of Civil Procedure include a provision for the case management of civil, non-family cases in Ottawa and Toronto. ${ }^{17}$ At the inception of the OMMP pilot project in January 1999, approximately 43 percent of all civil non-family actions commenced in Toronto were randomly selected for case management. Now, r. 77 applies to all civil actions and applications commenced in Toronto, Ottawa and, as of 31 December 2002, Windsor. Case management is a system wherein court supervision is provided through the management of individual cases with the objective of moving cases through the justice system in a timely and effective manner. It entails regular meetings with the case management Master assigned to a given action and the imposition of strict deadlines for each of the various stages of the litigation.

The thinking is that mandatory mediation naturally dovetails with the existing case management system, given the common goals of improved efficiency that both concepts include. Mandatory mediation early in the litigation process was intended to be another component of the case management system designed to improve the civil justice system by reducing costs and time delays and by promoting fair and early settlement of actions. Given the recent events in the Toronto Region surrounding the suspension of many components of 
case management, including early mandatory mediation, there is a claim being made that these objectives of efficiency may not be being achieved under the current regime.

If an issued claim falls within the subject jurisdiction of mandatory mediation, the plaintiff must, within 30 days of the filing of the first defence in the action, file with the Local Mediation Coordinator a notice stating the name of the mediator selected by all the parties to mediate the case and the date for mediation, within 90 days. If the plaintiff fails to file this notice within the prescribed period, the Local Mediation Coordinator oversees a system whereby a mediator from the roster is randomly selected and assigned to conduct a mediation of the case within the original 90-day time frame. The assigned mediator is required by the Rule to set down a time for the mediation session, working within the 90-day window, and to conduct a mediation of up to three hours in length. The maximum fee that that mediator can charge the parties for the preparation for and conduct of that mediation session is prescribed by the Regulation passed pursuant to the Rule. ${ }^{18}$

While there exist conditions for achieving a postponement of mediation, the clear intention of the program is to have each case falling under its governance mediated within 90 days of the filing of the first statement of defence.

\section{E. FINDINGS OF THE INDEPENDENT EVALUATION}

As noted earlier, a third party evaluator was hired at the outset of the OMMP pilot project to evaluate the effectiveness of the program. It was this evaluation that was intended to assist the Ontario Ministry of the Attomey General in determining whether mandatory mediation was a program that would complement the existing case management structure and lead to increased judicial efficiency.

The evaluation subcommittee of the Civil Justice Committee, working with the program evaluators, arrived at the following findings based on their analysis of quantitative data collected randomly from mediators, lawyers and disputant parties participating in the mandatory mediation pilot project:

1. Mandatory mediation significantly reduces the time required to dispose of an action;

2. Mandatory mediation has resulted in decreased costs to litigants;

3. Mandatory mediation has resulted in a high proportion of cases ( 40 percent) being completely settled earlier in the litigation process;

4. In general, lawyers and litigants expressed satisfaction with the mediation process under r. 24.1; and

5. Although there were some variations, these positive findings applied generally to all case types and to cases in both Ottawa and Toronto. ${ }^{19}$

11 For example, the maximum fee for a two-party mediation is currently set at $\$ 600$ (to be divided between the parties), which includes the mediator's preparation time and the conduct of the mediation itself. With three parties, the maximum fec increases $10 \$ 675$, and so on (ibid, s. 4).

19 Robert Hann \& Associates, Evaluation of the Ontario Mandatory Mediation Program (Rule 24,1): Executive Summary and Recommendations (Toronto: Queen's Printer, 2001) at 2. 
As such, the evaluation group recommended that $r$. 24.1 be continued in its current application in Ottawa and Toronto, and ultimately extended throughout the province, a plan that is arguably underway with the addition of Windsor in 2002.

It is questionable whether a qualitative evaluation of the pilot project might have produced another layer of valuable data with which to complete the program evaluation. By beginning to understand what mediators think about what they do, we will be in a better position to surmise the nature and extent to which the theory behind concepts like party selfdetermination and mediator impartiality translates into practice.

\section{The Design of the Study: Phenomenograpuy as Grounded Theory}

\section{A. RESEARCH METHODOLOGY}

I approached this project with a great interest in the ways in which mediators conceptualize what it is that they do. This is surely the first small, albeit central, step towards understanding what mediators do. Before any meaningful analysis of mediator behaviour can be undertaken, we must consider how mediators think about mediation. While their perceptions about mediation, as expressed in my interviews, may not necessarily correspond with their behaviours as mediators, it is nevertheless valuable to understand how a group holding in common the phenomenon of mediating on the OMMP roster expresses conceptualizations about that phenomenon. My particular interest was to begin to understand, especially in the context of a mandatory mediation scheme, if mediators see themselves as oriented towards settlement or otherwise, and what mediators think about their own power within the mediation process.

In terms of generating the data on these questions, I considered both quantitative and qualitative approaches. While a survey would have likely generated a greater volume of response, my concern was that I would not have the flexibility to explore with the participants issues as they arose through the process of answering questions. Developing a set of patterned questions for a survey instrument might have eliminated the possibility of participants going in a direction that I had not anticipated and that led to valuable insight. Rather, given my focus on mediator perceptions dealing with sophisticated and potentially sensitive concepts such as power and personal orientations, I opted for a method of open interviews using a set of loose question sets and probes, so that participant elaboration and redirection would be encouraged and so that I might observe the patterns in conversation as they developed.

This approach is consistent with a view that I share respecting the development of mediation theory. Historically, our field's theory has developed in the shadow of its practice, as scholars scrambled to catch up to the practitioners. ${ }^{20}$ As a result, we operate under certain assumptions respecting what is meant by "mediation" and its components, yet we have spent little time testing those assumptions and more clearly defining our conceptualizations of 
mediation. To generate data based on a survey or questionnaire with questions shaped by my perceptions of mediation would be to reinforce this situation. It was my hope from the outset to be highly elicitive and reflexive in the collection of data, allowing for data to emerge in patterns and approaches that had not been preconceived by me. To achieve this, I chose a methodology that would permit this flexibility and reflexivity.

By adopting an open-ended interview structure for my methodology, I was able to ensure that any theories that I developed as a result would be properly grounded in the material examined and not imported from outside of the study. I am not suggesting that these new, emergent theories are unconnected from established theories existing outside of the study, as they are most properly considered as one strand in a web of contextual theories informing this field. However, by grounding emergent theories firmly within the study itself, the researcher is able to avoid, or at least minimize, the temptation of interpreting the data so as to "fit" it into pre-existing theory.

From the outset of this project, I was concerned with bracketing my own presence in the process, given that I have been a practicing mediator on the Toronto roster since its inception. Certainly, there is a valid concern in ethnographic work that an interview respondent will react to their construction of the interviewer. That said, as Kenneth Kressel noted on this issue,

[i]n choosing to study ourselves, my colleagues and I made what, from the perspectivc of traditional research design, is a highly controversial, even unacceptable decision. In the traditional view, objectivity becomes impossible from such a vantage point. So strong is the power of the traditional empiricist ideology that even refleclive practitioners rarely turn the reflective research lens on their own practices. ${ }^{21}$

Borrowing from the views of Donald Schön, Kressel ultimately justifies such a research vantage point within the subject field by claiming that, the potential problems of bias and subjective distortion aside, practitioner research such as this is likely to result in a highly motivated researcher driven to identify mediator perceptions as these are issues that have directly captivated the researcher herself. Provided that the practitioner researcher is able to acknowledge and bracket her own presence in the research, it is suggested that the meaning of the data generated will be more readily grasped and the shared cultural common ground between researcher and subjects will create an environment much more conducive to rich and reflective discourse. ${ }^{22}$ I followed a number of suggested strategies for bracketing my own presence in the research, the most important of which was to continually acknowledge my own connection to this study and to be highly cognizant of that when interviewing respondents and analyzing the emergent data.

\section{B. PHenomenography}

As one of various applications of the grounded theory method, phenomenography operationalizes a research interest in the discovery of regularities and discerning patterns of

: Kenneth Kressel, "Practice-Relevant Research in Mediation: Toward a Reflective Rescarch Paradigm" [1997] Neg. J. 143 al 146.

$\because \quad$ lbid 
conceptualization. ${ }^{23} \mathrm{~A}$ research approach designed to answer questions about thinking and learning, phenomenography was originally developed by a research group in the education department of the University of Göteborg. Sweden ${ }^{24}$ and was later coined as a term in 1979 by Ference Marton, also of the University of Goteborg. ${ }^{23}$ Simply stated, phenomenography is "a research method for mapping the qualitatively different ways in which people experience, conceptualize, perceive, and understand various aspects of, and phenomena in, the world around them." ${ }^{26}$ Phenomenography is most often found in the study of education, yet has application to a variety of topics aimed at addressing participant conceptualizations.

In particular, phenomenography is equally interested in entirely mistaken conceptions of reality held by those who experience a given phenomenon. To the phenomenographer, that a group of people participating in a phenomenon hold to be true a completely false view of that phenomenon is at least as interesting as a group of people who conceptualize the obvious truth and a common meaning of a given phenomenon. As such, Marton posits that "phenomenography occupies a space somewhere between natural science (disciplines that deal with what we hold to be true about the world) and traditional social sciences (which seek to discover the laws of mental operations and social existence)."27

The standard method of phenomenographic inquiry is to engage in loosely structured interviewing "conversations." In order to ascertain the subject's meaning, phenomenographic interviews require the investigator to employ both reflection, whereby the subject's ideas are restated for clarification, and follow-up questions, again intended to clarify the meaning intended to be expressed by the subject. Unlike other more widely used research frames, phenomenography is sufficiently flexible, or arguably underdeveloped, to permit a variety of analytical methods. In her 1993 study on education meanings, Joyce Stalker noted that phenomenography is "more about the end goal of uncovering conceptions than it is about a process of data analysis."

What of the outcome of phenomenographic research? Phenomenographers

categorize their subjects' descriptions. and these categorizations are the primary outcomes of phenomenographic research... When we read and classify descriptions of a phenomenon, we are not merely sorting data; we are looking for the most distinct characteristics that appear in those data; that is, we are looking for structurally significant differences that clarify how people define some specific portion of the world. 29

Or, as noted by Lannert Svensson and Jan Theman, the objective of phenomenography is "not to describe the data in more general or abstract terms but to differentiate, group, and

2 Reneta Tesch, Qualitafive Research: Analysis Types and Sofnware Tools (New York: Falmer Press. 1990) at 63,65 .

it Ference Marton, "Phenomenography - A Research Approach to Investigating Different Understandings of Reality" (1986) 21:3 J. Thought 28 at 28.

" $\quad$ bid. See also Ference Marton, "Studying Conceptions of Reality - $A$ Metatheorelical Note" (1981) 25 Scand. J. Ed. Res. 159.

3. Marton, supra note 24 at 31 .

$37 \quad$ Ibid. at 32.

in Joyce Stalker, "Voluntary Participation" (1993) 43 Adult Fd. Q. 63 at 67.

2y Marton, supra note 24 at 33-34. 
interrelate data and then characterize the result in the form of categories of description." ${ }^{30}$ Central to this methodological approach is the "dialectical" approach to determining these eventual categories, in that they are not determined in advance but which, rather, flow from the comparison of emergent ideas and comments from the interview texts. As commonalities emerge, so too do categories begin to form, and ultimately the boundaries of the forming categories determine which quotes and ideas should be included and which should be excluded from a specific category. Through the repeated sorting and resorting of data, category boundaries and definitions are continually tested against the data and adjusted accordingly. The phenomenographer hopes that eventually, as is the pattern, the rate of change will decrease until the entire system of meanings represented by the categories is stabilized. ${ }^{31}$

\section{Application of Phenomenograpily to this Study}

What is most appealing about the application of this approach to investigating mediator's conceptualizations is phenomenography's ability to group individual perceptions into common categories of meaning. By engaging in an investigation of how mediators construct their reality, we can learn a great deal about the beliefs, assumptions and motivations that drive them as actors.

It was my hope at the outset that data emerging from the interviews conducted for this study would support the notion that mediators conceive of mediation and power is several common ways. As phenomenography does not imply that its resulting categories of meaning are transmitted among participants, the relative isolation of the members of the group that I have chosen is well suited to this approach.

I anticipated this outcome of the research would be particularly interesting as I expected to discover little if any interaction among members of the group that I selected for participation. Despite the separation of members of this group, a phenomenographic approach permits the suggestion of commonalities in their conceptualizations of the practice in which they engage, mediation.

Unlike other professional groups, it was my suspicion that there is far less interaction and communication among mediators respecting the nature of mediation and what it is that they do. In fact, having now completed the study, I can confirm that mediators in this sample widely identified their professional isolation from others practising in the field. When prompted, no one seemed able to explain this isolation, but many appeared dismayed by it.

\section{Selection of the Study Site and Participants}

Much of my interest in mediator power was generated by a curiosity as to whether mediators operating within a mandatory mediation scheme would be more likely than those 
practising in other models to experience an orientation towards settlement in the mediations they facilitate and if so, to examine the ways in which those mediators might attempt to achieve that settlement by harnessing the power available to them. It was my initial thought that any orientation towards settlement would likely be more evident within the context of a mandatory mediation scheme, given its clear settlement objectives. With that in mind, the most natural site for my study was the OMMP. The OMMP remains one of the few comprehensive mandatory models currently being implemented in Canada. Additionally, it boasts a substantial roster of mediators in each of its three operational cities, and each of these mediators has been selected on the basis of education, training and mediation experience to sit on the roster. It was my hope that having such a rich source of subject mediators would lead to a wide range of variant conceptualizations of mediation.

\section{E. THE INTERVIEWS}

This study was based upon an open invitation to all mediators registered on the mediator roster for Toronto, asking for an expression of interest in participating in "a study of mediators' views on the mediation process." Ultimately, 26 mediators agreed to participate in the study, a number that was reduced to 17 actual interviews due to changes in personal circumstances, scheduling difficulties and illness. On average, each interview lasted approximately 90 minutes in length and could aptly be described as "conversational," with my introducing topics in an extremely open-ended way so as to elicit the respondents' conceptualizations and views as spontaneously as possible. The actual topics introduced into these conversations were organized in a question set that I refined through a pilot phase of this project conducted before the main interviews comprising the database.

There are any variety of approaches to intervjewing in qualitative projects. I was most significantly guided by the social constructivist framework adopted by James Holstein and Jaber Gubrium in their text, The Active Interview. ${ }^{32}$ They argue that all interviews are "interpretively active, implicating meaning-making practices on the part of both interviewers and respondents." 33 While they do not propose a specific inventory of necessary interviewing methods, Holstein and Gubrium suggest, rather, a theoretical framework for viewing the interview that I found to be quite compelling.

These theorists contend, consistent with many feminist scholars in the field of qualitative inquiry, ${ }^{34}$ that the interview cultivates the making of "meaning" as much as it generates data. They suggest that the actual subject of the research being conducted is someone who lies somewhere behind the interview respondent. Rather than the conventional understanding of these subjects as "vessels of answers" for the questions posed by the interviewer, Holstein and Gubrium contend that rather than this passive participation, a construction of the subject as active recognizes not only the facts and details of the subjects experience as related, but

12 James $\wedge$. Holstein \& Jaber F. Gubritum, The detwe Interview (Thousand Oaks: SAGE Publications, 1995).

" lbid. at 4.

34 Shulamit Harding, ed., Feminism and Methodology: Social Science /ssmes (Bloomington: Indiana University Press, 1987); Sandra Reinharz, Feminist Methods in Social Research (New York: Oxford University Press, 1992); Dorothy E. Smith, The Everyday World as Problematic: A Feminist Sociology (Boston: Northeastern University Press, 1987). 
also creates meaning by the way in which the story is related, thereby transforming the facts and details along the way. ${ }^{35}$

This theoretical framework expands to include the interviewer herself as an active participant in the meaning-making process. While traditionally, interviewers are taught to receive information without giving any back to the subject (in the hopes of avoiding the interviewer's thoughts impacting on subsequent answers given by the subject), ${ }^{36}$ the perspective advocated by Holstein and Gubrium is very different. They note that an interviewer's attempt to remain uninvolved in the process typically fail, citing research that indicates that at least 50 percent of everything that an interviewer says after the beginning of an interview is something other than either a designed question or a neutral probe. ${ }^{37}$ Clearly, despite training to and perhaps intention to the contrary, interviewers engage in conversations with the respondent that are central to the research being conducted and the data ultimately collected.

These theorists suggest an alternative framework that places the active interviewer in the role of provoking narrative from the subject by intentionally suggesting ways in which the respondent might conceptualize their views and responses to the research questions. This approach is far less purely facilitative than the standard conventions respecting interviews. While the active interviewer does not tell respondents how a given question is to be answered, with the objective of inciting a narrative response, he often will "poke" the respondent into providing more reflective and analytical answers by suggesting frameworks, categories or labels for the respondent's view, which are either accepted or rejected by the respondent but which are, in any event, elaborated upon. That is the objective of active interviewing, where the respondent and the interview actively collaborate to construct meaning of the interview.

One of the most interesting issues that arose from these interviews as a result of this approach was the common view held by the mediators I worked with that their practice is one of, at times, lonely and disconcerting isolation. As many of the mediators I spoke with have a background in legal practice, this seemed so foreign to them, coming from a culture that tends to be very group-oriented. Given what one respondent called the "philosophical underpinnings of the mediation movement" several indicated their surprise at not finding a collectivist spirit about the practice of mediation and were puzzled as to the explanation for this. This was something that emerged from the interview narratives slowly - largely because I rejected it at the outset. It was not a reality of mediation practice that coincided with my own.

In terms of the questions themselves, I generally began with some background information in order to "break the ice" and to establish some comfort and rapport in the interview. By

1s Holstein \& Gubrium, supra note 32 at 8.

". Sec e.g. Charles H. Backstrom \& Gerald D. H lursh, Sunvey Research (Chicago: Northwestern University Press, 1963) at 135.

" C.I. Cannell. G. Fisher \& K.H. Marquis, The Infuence of Interviewer and Respondent Psychological and Behavioral Variables on the Reporting in Household Interviews (Washington, D.C.: U.S. Department of Health, Education and Welfare, Public Health Service, 1968), cited in Holstein \& Gubrium, supra note 32 at 38 . 
encouraging the participants to talk about their education and practice backgrounds, any discomfort with the interview process was reduced. We then discussed various philosophical aspects of mediation as I guided the respondents in talking about their own idea of what mediation is and what it is intended to accomplish. In particular, I asked each participant whether their own goals as a mediator mirrored what they saw as the bigger objectives of mediation. We then discussed success in mediation; in particular, how as a mediator one measures success.

After discussing a number of process issues in mediation (that is, confidentiality, neutrality and process management frameworks), we then engaged in conversation about the role of power in mediation. 1 avoided supplying my own definitions of power and allowed each participant to describe and define mediator power as they viewed it before explaining how that power is used, or not used, in a mediation session. While this approach aided in bracketing my own presence in the emergent data, it also led to some fairly conventional (and admittedly limited) frameworks of power being used and applied. We talked about sources of mediator power and then wrapped up the interviews by my asking if there were any other comments the participant would like to add. On average, each of these interviews lasted approximately 90 minutes.

\section{F. Data Collection and Anal.ysis}

The analysis that I engaged in was highly iterative in nature. By continually reviewing the data collected in the holistic context of the interview in which the data was offered, a number of categories and themes began to emerge.

The formal analysis of this study was conceptually divided into three stages: individual data review, preliminary data categorization and contextual refinement of categories. Although the suggestion is that this was a linear progression through phases in the analysis, this was actually a cyclical process, so that any analysis that I considered was continually checked and re-checked against the data. It is also superficial to imply that there were three discrete stages of data analysis. Of course, along with the cycling back into earlier stages that occurred throughout the process, there was a recognition of the blurred boundaries between one stage and the next.

At the third stage of analysis, clear categories of mediator perceptions were revealed and confirmed. I remain convinced that over 75 percent of the interviews conducted led to a dominant conceptualization of mediation that corresponds to one of the three categories. I do not propose that these categories represent distinct mediator profiles; rather, they reflect groupings of mediator conceptualizations that hopefully suggest some of the key ways in which mediators perceive of the process and their role within it. In terms of the uitimate audience for these findings, $I$ believe that these cluster categories will provide the basis of some rich reflection for both practitioners and theorists alike, encouraging a more reflective approach to thinking about our craft. 


\section{Findings I: Mediators' CONCEPtions of MEdiation}

As noted earlier, phenomenographic research anticipates the emergence of specific conceptualizations of a given phenomenon and the grouping of these conceptualizations into categories of understanding. In her phenomenographic study of the concept of participation in adult education, Joyce Stalker notes, "for phenomenographers, conceptions are characteristic not of individuals, but of ways of functioning within an outcome space ... the identification of conceptions, not of who holds them, is of primary importance." ${ }^{138}$ As such, the analysis of the data generated by this study is not intended to establish descriptive categories of individual mediators, but is rather aimed at uncovering a variety of views of mediation and its components that emerged through the process of active interviewing.

As with other applications of grounded theory, the philosophy of phenomenography asserts the legitimacy, as a research goal, of presenting a variety of conceptualizations of the targeted phenomenon, without suggesting the relative frequency with which the various views are expressed, or an evaluation of the subjects who hold each different view. With that in mind, the following analysis does not undertake to report on the relative dominance of each of the conceptions addressed.

This study does not attempt to draw conclusions based on constructing correlations between certain conceptions and demographic information. Rather, my intention is to illustrate the range of conceptions expressed by the interviewed mediators on a variety of topics. From there, certain groupings of those conceptions will be constructed in the form of categories so as to suggest, loosely, some general views on the mediation process as held by this group of participants.

While my initial intent was to simply describe the conceptions of mediation as discussed by the respondents, I quickly found that these conceptions were often "buried" and emerged only when a global consideration of the various elements of and approaches to mediation was undertaken. As such, before I was able to suggest some categories of mediators' conceptions of mediation (which I do in the latter part of this section), I first needed to consider the ranges of conceptualizations of mediation as expressed by the mediators. Only after considering these conceptualizations was I able to draw any categorical groupings of conceptions of mediation.

\section{A. CONCEPTIONS OF TIREE EI.EMENTS OF MEDIATION}

After iterative reviews of the interview data, I decided to consider mediator perceptions of the following three elements of mediation as background to the larger categories of mediator conceptions that follow:

1. The Philosophy of the Mediator in the Context of Measuring Mediation Success;

2. The Goals of the Mediation Process in the Context of the OMMP; and

3. The Process of Mediation. 
While there are certainly various other conceptions worth tracking, a line needed to be drawn somewhere between having too few themes from which to draw categorical groupings and having every single conception that was expressed in the interviews included in this consideration. As a group, I propose that the three themes cover those elements of the mediation that emerged as most central from the perspectives of the mediators themselves. Each interview touched on all of these themes, and in many cases, the respondents chose to elaborate on their views surrounding these themes at great length in the discussions.

I suggest that the commonality of these themes will ensure a greater degree of accuracy in my communication of mediator conceptions, as I have a significant amount of data from a variety of mediators to interpret. This, as opposed to the situation where I am drawing conclusions based on an idea that was only briefly touched upon in three interviews. While a theme raised in that scenario may be equally cogent, it is fair to conclude that such a theme is not a pressing concern or interest of the mediators in this sample and, as such, may be insufficient to contribute to a categorization of the conceptions held by this sample of mediators.

\section{CONCEPTIONS of Mediator Philosophies Surrounding THE MEASUREMENT OF SUCCESS}

I noted several distinct approaches adopted by the interview respondents in expressing a philosophy of mediation. Many mediators suggested that mediation philosophy was driven by the program in which the mediation was being conducted. More on that idea will be discussed in the next section on the goals of the OMMP. Also prevalent was the idea that there is a distinct and static philosophy of mediation, irrespective of context. Mediators who expressed this view invariably espoused a personal philosophy of mediation that directly corresponded with this overarching philosophy.

One of the themes that I found to be most illustrative of a mediator's personal philosophy of mediation was in the way in which she or he claimed to measure success in mediation. Invariably, the measure of personal success was aligned with what that mediator believed to be the philosophy of mediation. Considering the emergent data, the following conceptualizations of mediator philosophy in the context of measuring success are most representative of the ideas expressed by the sample of mediators interviewed.

\section{S1: "Mediation is successful if the mediator sets an example of how to handle conflict"}

Very few of the mediators participating in these interviews referred to the philosophy of empowerment and self-determination, which often emerges in discussions about mediation philosophy. Any reference to goals of empowerment or transformation were generally offered to illustrate the contrast with the perceived objectives and philosophy of mediators operating within the mandatory scheme.

Some of those mediators whose practices include the conduct of mediations outside of the mandatory model spoke of empowering parties (for example, in family mediation) and specifically declared that such an outcome is not possible within the mandatory scheme. 
Those mediators often expressed that the closest they came to such a philosophy when working within the mandatory scheme was to measure their own success by helping the parties to manage the existing and, potentially, future conflict in a more productive way.

One respondent indicated a changed attitude towards success in mediation from when he first began his practice:

Al the outset, when I had a mediation that settled, I was elated and it gave me a personal boost. When I had been unable to help parties to resolve the conflict, I felt I had failed.... Yet I have learned that not accomplishing settlement is far from a failure, even within the mandatory mediation framework. If the mediator is able to set an example of how to handle conflict and if they didn't settle but the mediation process has changed something positively, then you are making a change in the parties for the better and that is what it is all about.

To illustrate the schism between mandatory and voluntary mediation schemes discussed above, one respondent discussed success in two distinct contexts:

The thing that really makes me feel like l've done a good thing is when the clients have reached a new level of insight into themselves and into each other that wasn't there before. That is really the best measure of success.

$Q:$ Is this the same indicator of success, regardless of whether it's a mandatory or a voluntary model of mediation?

Of course not! In the mandatory model, success is only about setlement... Was a settlement possible? If not, have I at least narrowed the issues? If a resolution was possible and I got them there, then that was a great success for me. You measure success differently here because there is not room in the model for personal insight. No room in the process for people to connect to each other as human beings.

Similarly, another respondent made distinctions between the philosophy employed in his mandatory mediation practice and how he approaches success in his mediation practice implementing the therapeutic family medjation model:

[I]n the therapeutic family mediation model, success is oflen measured by cach parent being confident that the other parent is competent and should therefore be able to make effective parenting decisions ... in the OMMP, cascs rarely involve an ongoing relationship. They don'l care about cach other; all they want is the money. As such, I have virtually no opportunity to use my skills and interventions. The roster program has tied my hands so that success is measured only by my ability to setile a high percentage of the cases that I am assigned. And so my philosophy may be about helping people to handle conflict better but in this case it gets transformed into searching for a sertlement oppertunity.

\section{Similarly, in the words of another respondent:}

I measure my success in non-roster cases very differenlly than in the mandatory roster cases. In the non-roster cases. I see mediation as being about relationships and the parties' sense of well-being, both collectively and individually. Those cases simply mean a whole lot more to me; they are far more challenging and personally satisfying than the roster cases. 
Yet, even within the suggested confines of the mandatory mediation model, some respondents emphasized the mediator's opportunity to impact on the way in which the parties approached the conflict and each other. One respondent, a lawyer-mediator, focused on his ability to improve the relationship between the parties for a positive impact on the future of the litigation in issue, noting:

I have never measured my suceess by settlement. In fact. I don't even keep track of my own settlement rates.... ['ve had cases settle, but when I walked out of the mediation, I just diơn't feel good about it. Maybe I don't feel good about what I brought, or failed to bring, to the process... Other limes, l've walked away from a mediation that didn't settle and just felt terrific about what I did and how I approached it and the fact that I was helpful. That I was able to sel a tone that wasn't "touchy feely," but a tone of warmth and mutual respect that I could model for the parties. When I am able to bring that to the process, it creates an environment where egos deflate a little bit, where people aren't posturing quite as much and where they interact better in the litigation as a result. To me, that is what mediation should be about.

Perhaps the closest articulation of a measure of success approaching the transformative end of the mediation continuum in terms of weighing mediator success came in the following comment:

My philosophy of mediation is based on a belief that the adversarial methodology in our society is not a solution. It is not workable. One party may win in the short-term, but the other will be so resentful as a result that they will strive to get back at the first party. Somehow ... mediation is about working to make each other's differences acceptable. The differences may not be changeable or resolvable, but things can be put into place to make them "liveable" at the very worst.

The next set of conceptualizations moves away from the perception of mediation as focused on the relationship of the parties and towards the end of the spectrum seeing mediation as primarily about resolving the dispute at hand.

\section{S2: "Mediation is about helping people look realistically at their options and strategies"}

This view of measuring the success of a given mediation session focuses on assisting the parties, not in their interpersonal relationship, but rather in achieving a more realistic assessment of the conflict in issue. As parties regularly come to mediation with mutually inconsistent views of their conflict, mediators who express this perspective see themselves as successful if they are able to convince each party to reconsider the relative merits of the other's position. Arguably, this behaviour is seen as successful as it puts the parties along the path to settling the dispute. With that in mind, it could properly be included in the third conceptualization of success (stated below) as the ability to help parties settle the case. However, I felt that the explicit exclusion of settlement from the way in which these mediators expressed success warranted a separate consideration. For example, one female lawyer-mediator specifically excluded settlement from her measuring success, noting:

As long as I've done my best, l'm not going to walk out of here distraught because it doesn't settle and I will get paid whether it settles or not... I'm absolutely not driven by whether it settles or whatever... I always talk very frankly to people about the emotional and financial time costs, especially in cases where there seems to 
be a huge disparity in money ... and power.... How do I measure my own personal success? When I am operating within the [OMMP] roster, it is all about helping people to look realisticaliy at what the options are available to them.

Similarly, when asked about her measure of success in mediation, another mediator answered:

That's easy! I always try to help people who are in this conflict situation to each develop their own best strategies and to look to the future and weigh their options and then make an appropriate decision respecting whether or not to settle and on what terms.

What I found particularly interesting when asking mediators about how they each "measured personal success" in mediation, was that a notable number of them first offered that mediation success was not about settlement and then proposed their alternative tool for measuring success. This, despite the fact that my question about measuring success made no mention of settlement as a possible yardstick. For example, one mediator responded as follows:

I try really hard not to go into a mediation married to the idea of settlement or thinking that l'm such an important part of the process. It's not really about settlement and I am only one small element of the dynamics at the table ... whether there is ultimately a settlement or even a better understanding of each position has to do with a lot more factors than just what I bring to the table. But I can help with that understanding, I think.

Another mediator prefaced her comments on measuring success as follows:

I measure success by whether or not the parties have really talked about the actual issues. I don't measure it by whether or not there is settlement. Because, in my experience, it is rare that a full settlement is achieved at mediation... I feel that once you get people to talk openly, even if they don't come to a settlement, the whole ball game is different. Whatever happens next in the process, they have already had this one conversation at least ... in a sense, mediation can be a warm-up session, even if they don't settle, to some real honest search for a solution.

Another mediator had developed a particularly interesting practice of plotting each of her mediation sessions, directly following its conclusion, onto a four-quadrant matrix. Across the top, she has two quadrants devoted to the positive and negative aspects of the mediation session; the two lower quadrants further divide these aspects into those qualities, positive and negative, of the session that were and were not within her control. Only by engaging in this "debrief" and considering the resulting lists following each mediation does she determine if she has been successful. As she offered during our discussion:

Obviously, reaching an agreement is no measure of either success or failure. You might have dorie a crappy job and yet they still agreed. Or, you might have done a really good job and they didn't agree. Settlement is simply no measure.

Finally, the next set of articulations about each mediator's measure of personal success in mediation is situated towards the "settlement" end of the continuum. While it is recognized that phenomenography is explicitly not about rates and frequencies of responses, it is 
noteworthy that a significant majority of mediators measure their personal success by settlement and expressed conceptualizations of success that are represented by the quotes included in this next grouping.

\section{S3: "Mediation is clearly about settling cases!"}

One of the most interesting commentaries on those mediators who define their success through the settlement of mediated cases surrounds the fact that a significant number of them explicitly denied this definition during the portion of our interview that focused on measures of success. That is, while some of the mediators who conceptualized mediation success as measurable by rates of settlement were very explicit about this conceptualization, others who I also have included in this philosophy initially denied that they measured their professional success by the settlement of cases. It was only after completing a contextual consideration of my field notes taken during and following the interviews that I concluded some internal inconsistencies within the claimed objectives of this group of mediators.

Why would a mediator deny that success was about settling cases and then clearly indicate the contrary through other parts of the interview discussion? Query whether there exists among mediation practitioners a sense that mediation is, at least theoretically, intended to be about something other than settling litigated disputes. Case in point; several of these respondents, who I have labelled "latent success seekers," clearly stated that mediation was to be about improving relationships and that they measured their own success by the extent to which they had achieved this goal. Yet, later in the interview, they made comments that directly overruled the former ones in highlighting case settlement as their primary goal, at least when mediating within the mandatory scheme of the OMMP. I asked one mediator how she measures her success, to which she replied:

I get the strongest sense of satisfaction when I leave the session and am convinced that I did everything possible to resolve the conflict and facilitate resolution; where I left no stone unturned and used alt the tricks in my bag... It is not about settlement. One time I left the mediation without a settlement and still felt great about what 1 had done.

\section{Q: Could you elaborate on that? Why did you feel great, exactly?}

Sure. I told the parties that I wouldn't be submitting the mediator's report [indicating the case had not settled] until I could spend some more time going back and forth between them after the mediation to see if I could work something out. I spent the next ten days shuttling back and forth between the parties. finally achieving a settlement. I felt very successful that time, but the settlement was irrelevant.

Despite her comments, it struck me that she measured success very much according to whether or not a settlement had been achieved. I remain convinced, however, that the more interesting question is to ask why these mediators feel compelled to deny that success is all about settlement?

Later in our conversation, this same mediator who had earlier adopted this alternative "rhetoric," denying that success was about settlement, recounted the story of a case she mediated involving a lawsuit brought by a man against his mother and the extreme emotion 
that resulted from their close ties. She reported that at the end of this very long and exhausting mediation, she felt it was one of her most successful ever. When asked why it was her most successful mediation, she replied "because it settled" and the "relationship angle was an added bonus."

Of course, in many cases, there was no such compulsion. As one mediator put it:

In the mandatory model, I measure my success by, really, has it setlled. Was it possible to get a setllement? If nol, but $I$ have helped narrow or settle some of the issues, Jine. If a resolution was possible in my view, and they got there, that is a great success for me.... You measure success differently here jin the mandatory scheme] because there is no room in the model or in the process for personal insight. There is no room in the process for people to connect to each other as human beings.

While clearly this mediator admitted that success was attributed to settlement of the dispute, she also explains why satisfaction must be marked differently in the mandatory model. Again, I would suggest there is an unspoken belief that measuring success by settlement is somehow less legitimate than using other yardsticks, despite how disconnected these latter alternatives are from the mandatory mediation model. As one mediator firmly stated:

I always feel the best about my own achievement if $I$ come out of a roster mediation and it has settled! There is not a lot of gratification in improving communication or the relationship but not senting ... that just isn't a measure of success in these roster cases. The real issue is trying to resolve the conflict, to work it cut. It sure isn't about long-term relationships and their repair.

Yet, there are still other examples of mediators who clearly included themselves in the camp that believed success was about settlement, but who were not compelled to explain or justify this position in light of potentially more "lofty" measures of success. As one man said:

I measure success in several ways. I am very settlement oriented and keep very close track of my settement rates. Currently, I am above 50 percent, which I know is good. My greatest satisfaction comes when the lawyers leave the room and thank me for making "it" happen. The "it" can be either settlement or nearsettlement... I am always the happiest when I get a settlement and even happier if both parties are satisfied with that settlement. I also feel good if I manage to maintain control of very diflicult parties. I am the most disappointed if a mediation does not produce a settlement and I was unable to convince the parties to get realistic and just settle the problem.

Another mediator explained success this way,

Success is subjective. Even if they don't settle in the [mediation] session. ifl have put them on the shor path to sentement, I feel successful. I always feel great if I've directed parties towards settlement and even better if that settlement happens during my time with them.

\section{Q: Is it only about settlement, then?}

Well, if l've asked all the right questions and done all the right work and tried to push lowards settlement as much as I could, then I suppose I feel somewhat successful. Not "as" successful, but somewhat. 


\section{Conceptions of the GoAls of the MEDiation PROCFSS IN THL CONTEXT OF THE THE OMMP}

With the phenomenographic goal of suggesting categories of conceptualization in mind, 1 recognized that a thorough consideration of these mediator groupings would need to include mediator conceptualizations of the objectives of the mediation process. In particular, given my interest in mandatory mediation, it was my intent to seek mediator perceptions of these goals within the context of the OMMP, a system in which they all operated as mediators.

While I expected a correlation between the way in which a mediator describes the goals of the program in which she is mediating and her description of her own goals in mediation, I found this was not always the case. Perhaps it was my own experience that led me to anticipate, for example, that a mediator who operated in a scheme that he saw to have as its chief goal the empowerment of parties, would likely describe his own conception of mediation as being about empowerment. Similarly, I expected that he would measure his own success as a mediator within that program by the extent to which he was able to assist the parties in achieving such party empowerment.

While this consistency between personal and program objectives was certainly evident in some mediators' expressions, there were a significant number of mediators who were quite comfortable about expressing very different conceptions of what the program was aiming to achieve and what they themselves had as stated goals. In many cases, I would suggest that these distinctions were in fact mutually inconsistent, as I will illustrate below.

That unexpected dissonance led me to conclude that this range of conceptions needed to be individually considered in constructing representative categories of mediator conceptions. Again, we see some mirroring of the conceptions presented in the previous section on measuring mediator success, but the interesting analysis lies in the fact that many mediators who placed themselves at one end of the range in terms of measuring their own success, saw the program objectives and, therefore, "measures of success" as entirely different.

It should also be noted that the first conceptualization (Gl) below, viewing the goals of the program to be primarily the resolution of cases, was articulated by all but a handful of mediators and $I$ have no reason to believe that those few believed it to be otherwise. Rather, the context of those interviews suggested to me that this goal of increased settlement was so patently obvious as to render it unnecessary to mention. Rather, these mediators often chose to focus on other secondary goals of the program. I was particularly aware of my own presence in the research at this stage of the analysis, and careful to distinguish between goals that the mediators explicitly expressed, and those unspoken goals that I perceived the mediators to be implying by their comments; perceptions that may well have been my own being subconsciously projected onto the interview respondents.

All of the findings that are displayed in groupings below emerged from either a stated or implied premise that while settlement was certainly one of, if not the only, primary goals of the OMMP, there are other objectives worth noting. As such, groupings G2 and G3, respectively, below should be read as additional objectives of the program rather than alternative objectives to settlement. 
With that in mind, the following mediator conceptualizations of the goals of the OMMP emerged from the data as representative of clusters of ideas that this sample of mediators expressed in the interviews.

\section{G1: "The OMMP encourages early settlement, nothing more and nothing less"}

Not surprisingly, this interpretation was the one most frequently expressed by mediators in this sample when discussing the OMMP. This viewpoint was stated in a variety of interesting ways; some mediators seemed to be disappointed by this reality while others appeared far more supportive of this objective. That divergence seemed to correspond with the views held by a given mediator respecting the bigger objectives or "promise" of mediation. For many, the OMMP goal is to relieve court pressure, while some expressed the conviction that mediation is intended to be relational and empowering, so that a foray into increasing judicial efficiency is a discouraging "sellout." By who or to whom was never clearly articulated, yet in several interviews the notion emerged that "we" have somehow allowed mediation to be hijacked and mutated for some other, less legitimate, purposes.

It should be noted that in all of the interviews that were conducted as part of this study, not one mediator claimed the goal of the OMMP to be the improvement of relations between disputants or the enablement of access to justice through individual party empowerment or participation in the dispute resolution process.

I suggest that this narrow range of views is indicative of the success of the OMMP in communicating to its roster mediators the stated goals of the program. Harkening back to the Civil Justice Review that ultimately led to the implementation of mandatory mediation in Ontario, it is noteworthy to recall the Review's stated mandate: "to develop an overall strategy for the civil justice system in an effort to provide a speedier, more streamlined and more efficient structure which will maximize the utilisation of public resources allocated to civil justice. ${ }^{39}$ Even at its earliest conception, mandatory mediation in Ontario was to be about efficiency and costs, not about transformation and empowerment, and I suggest that mediators working within this model clearly perceive the model's objectives as related, in varying degrees, to increasing judicial case management efficiency. As one mediator explained:

Frankly, 1 find the statement in r. $24.1^{\text {t11 }}$ that mediation is to be interest-based totally incongruent with the reality of mandatory mediation. In the court-connected model, at least in Ontario, mediation is clearly and consciously about moving people towards settlement. There is not enough time or connection in the mandatory model to get to any meaningful interests or to try and transform the parties or their relationship as would be provided for in a truly interest-based program... Rather, the driving force of the roster is to clear out backlog and to move matters more quickly through the cour system, so that settlement is the be-all and end-all in many ways. of the Civil Justice Review, supra note 8 at 2 [emphasis added]. 
Another stated what he obviously saw as the positive objectives of mandatory mediation in Ontario:

The goals of the OMMP are clear: to eliminate the backlog. Traditionally, cases have been lawyer-driven rather than system-driven ... the roster aims to displace this control and to get the lawyers moving earlier in dealing with these matters. If we can force people to talk earlier in the piece, we always get more settlements.

One lawyer-mediator who has practised extensively in both civil and other disputes noted the following:

Let's be honest; mediation in the civil sector has been reduced to an adjunct of the court system. It's anly about settlement. It's a game. Sadly, that "magic" transformative quality so unique to mediation very seldom, if ever, happens on the civil side of mediation.

And a similar comment:

The OMMP is intended, first and foremost, to relieve pressure on our court system in Ontario. It gets matters to settle quicker and cheaper, hopefully. It doesn't necessarily get more resolutions than the regular litigation process, but it hopefully gets those results sooner. The main initiative is clearly about saving resources, as in time and money.

In addition to the aims articulated in this section, the next cluster of conceptualizations goes beyond the goal of settlement to suggest other purposes of mediation.

\section{G2: "The program is there to help people understand their interests and their motivations in terms of the conflict"}

Beyond a recognition of the settlement purpose of mediation, at least within Ontario's mandatory scheme, the following quotes are representative of comments made that suggest that mediation also had an educational component intended to assist parties in reflecting on their own motivations in terms of conflict. Also, this view of mediation's goals includes the intention of the OMMP to assist parties in accurately identifying their interests and needs in the hopes that they might find a more efficient way of meeting those needs and interests than that which is promised by protracted litigation. One mediator noted:

The goal of our mandatory mediation scheme in Ontario is to give parties an opportunity to settle a case early in the process where that is in the best interest of all parties... I also personally feel that the mandatory mediation program creates an opportunity for individuals to be real stakeholders in the process and to understand the conflict from a new perspective. Is this an actual "goal" of our system? Yeah, I think so.

Another mediator mused:

The goal of the OMMP is to loosen up the burden on the courts in a way which is effective for the parties; I think the hope is that the entire cour system will be revitalized by having a more elficacious process AND parties more aware of why they are there. 
It must be reiterated that there were not many conceptualizations that fell into either this or the following clusters. While other methodological approaches would be inclined to exclude these views as statistically insignificant due to their infrequent occurrence, phenomenography explicitly avoids this approach to data inclusion. Rather, it attempts to present varying conceptualizations of a given phenomenon or idea, regardless of how widespread the view. This idea, although infrequently expressed, did emerge from the data. As such, it is worthy of considering when reviewing the different views held by the mediators in this sample respecting the goals of the current OMMP.

\section{G3: "The OMMP, while not intended to empower people, does give} parties a chance to get their voices back and to use them"

This is an interesting cluster of data as, rather than stating a perceived objective of the OMMP, this batch of conceptualizations excluded from the intentions of the program any goals of party empowerment or participation, choosing to identify empowerment or participation or similar outcomes as secondary "by-products" of the process, whatever its goals. Sometimes mediators who made comments included in this group of conceptions and then proceeded to expand on what they saw as the explicit goal of the program, in which case their perceived objectives invariably fell with in the GI group of settlement objectives, stated above. As one experienced mediator put it:

The program goal is to get cases of the case management list. The goal is perceived by everybody to cut costs and speed things up. And that isn't a bad thing! There may also be some underlying goal of "this may be a better way to do things," but clearly what drives the roster is time and moncy.

When asked about the goals of the OMMP, another mediator had a similar view:

It would be great to answer that the goals of mandatory mediation are about improving relationships and all that good stuff, but realistically, the goal is to come up with a resolution that everyone can at least live with.

Nobody is going to end up happy, but if the relationships do improve, that's an unplanned bonus!

Clearly the responses to this phenomenon were more tightly clustered around a single idea (that is, the primary goal of settlement) than in other contexts used for analysis of this data. I have offered one possible explanation for this convergence; namely, the fact that the settlement objectives of the OMMP have been clearly and consistently stated since its inception. Again, those objectives are administratively emphasized by the form and content of the Mediator's Report, which collects data following each mediation only on the issue of settlement, partial or complete, and the time it took to achieve.

This focus on settlement was noted by several mediators during the interview process, in acknowledgement that clearly "the program" was tracking rates of settlement for the participating mediators. It strikes me that even someone completely oblivious to the stated goals of the OMMP would be unlikely to be unaware of the focus on resolving cases, and that such a focus is quite likely to impact on one's views surrounding the program and its goals. 


\section{CONCEPTIONS OF THE PROCLSS OF MEDIATION}

In terms of analysis methodology, the following section considering the process of mediation was approached from a somewhat different direction. In the previous two sections referring to mediator philosophy and mediator views of the objectives of the OMMP, these were topics that were directly discussed in the interviews themselves. As such, the data that emerged on these points was direct data, given in response to discussion of these topics. In this section, by contrast, that analysis is more inferential in that the topics focused upon below - flexibility and process management - were not topics directly discussed in the interviews. Rather, the data regarding mediator conceptions of flexibility emerged, for example, when discussing the use or non-use of the caucus as a component in the mediation process. Similarly, certain data emerged from our discussions on the approach to establishing ground rules that I suggest provide insight into that mediator's views on the flexibility of the mediation process.

Although this may appear as an oversight in that I should have directly discussed conceptions of flexibility and process management rather than having to infer views on these topics, it was an intentional exclusion. I wanted the opportunity to draw my own conclusions about mediators' views in these areas as I suspected that it would have been difficult to avoid suggesting desired responses from mediators if I had asked direct questions surrounding these topics. For example, if I inquired what a given respondent's views were on the issue of process flexibility, it would be hard to imagine a respondent replying that mediation is a rigid, set process. Rather, I anticipated that all respondents would identify flexibility as one of the key aspects of effective mediation and claim that the model they implemented was entirely responsive to the dynamics of a given case, with complete variation from case to case. To avoid this danger, I chose to get at flexibility conceptions in a less direct way, asking questions instead about the mediation models used and various process components.

Unlike the previous thematic consideration, there was extensive variation among the sampled mediators in regards to their perceptions of the process of mediation. They reported widely divergent views respecting the various models and components of the mediation process. While most mediators reported that they tended to utilize a specific model in the mediations that they conducted within and outside of the OMMP, they described varying degrees of flexibility in altering their preferred model and under different circumstances or triggers.

Similarly, also of interest was the extent to which mediators varied in their conceptualizations of appropriate intervention and management techniques that they employed, or didn't, in conducting the mediations themselves. For each of the thematic areas of flexibility and of intervention and management, three conceptions emerged from the data that are reflective of the mediators sampled. They can be summarized as follows. 


\section{a. Conceptions of Mediation Flexibility}

\section{F1: "What I bring is a process consistency that can be relied upon by everyone at the table"}

In analyzing the extent to which a given mediator implemented flexibility in the mediation process, the data provided many sources for this consideration. In the interviews conducted for this project, we discussed a number of specific components of the mediation process, borrowing from traditional mediation models. For example, in most interviews, we specifically discussed the mediators' views of the following process components: the caucus, the use and enforcement of ground rules, the "storytelling" model and the more general topic of process management.

Through an iterative consideration of these areas of the interviews, a number of conceptions repeatedly emerged from the data that comment on the mediator's views of the flexibility of the mediation process, despite the fact that we never specifically discussed flexibility. As noted above, I suspect that a direct question about flexibility of the process would have led to a homogeneous set of responses emphasizing the absolute flexibility of the process, while the data that emerged through this inferential process was far more diversified.

The first set of conceptions that appeared suggested an approach to flexibility that emphasized the standardized model of mediation process. Mediators whose views fell into this grouping provided comments emphasizing the regularity of the model or model component that they employed. A contextual analysis of these comments often gave the sense that these mediators identified the need for certainty in the process. Some mediators had clearly reflected extensively on the value of providing to disputants a clear and certain process model, while others appeared not to have given it much thought and seemed to fall back on whatever training they had received using a standardized model of mediation from which they had never varied. When asked about whether or not she uses the caucus in her mediations, one respondent replied:

Do I use caucus? Well, of course. It's a mediation process! I use caucus all the time because everyone expects it. Especially in the mandatory mediation cases. 1 suppose caucusing might not make sense in some situations where there are long-term relationships that need to continue, but you don't see that in mandatory mediation anyway.

When asked about what "triggers" the caucus, the same mediator replied:

Invariably, when the defendant finishes his story, there is a pause. That signals that they think it is time for the caucus. The mediation is about them, so I caucus.

In a similar vein, some mediators expressed their standard use of the caucus as a response to party or lawyer expectations. It is difficult to ascertain the truthfulness of this reasoning, given a number of other reasons that might more accurately explain a mediator's tendency to implement the same model in every mediation. In any event, the data emerges that a number of respondents deliver the same process in every session that they mediate. As one mediator noted: 
In mandatory mediation, it is clear that the parties expect to caucus. I do it quite automatically, and al ways fairly early in the session. Commonly, I caucus directly following the opening statements.

Of interest was the way in which some mediators distinguished their approach to mediating within the OMMP scheme and mediating in other contexts. The same mediator proceeded to clarify this automatic use of the caucus as follows:

In my family cases, I only caucus if $I$ think they are stuck and if there is information I believe they need to discuss in order to get "unstuck." Or, if there is escalating emotion or hostility. Or if one party appears to be seriously misinformed, I will caucus to point out to them in private that there is something they appear to have overlooked. I don't always use it, that's for sure.

Again, this distinction arose when one mediator was asked about his use of caucus:

In the OMMP process, I always use the caucus because everybody wants and expects it. It is always triggered automatically by the end of the storytelling phase... l ask if there are any questions and if not, everyone just sort of sits there expecting to split up, so I do. Generally, I meet in caucus first with the plaintiff to ask if their position has altered now that they have heard the defendant's position.

A similar approach to flexibility in the mediation process emerged when respondents discussed their views surrounding the use of "ground rules" at the outset of the mediation session. One mediator offered a comment that was highly representative of those offered by others in a similar vein:

I always discuss ground rules at the outset. I impose them. I decide what they are. My ground rules are the same every time: only one speaker at a time, and treal each other with respect. No yelling.

However, to be clear, the use of ground rules in itself does not infer an approach to flexibility on the part of the mediator. Rather, it is the extent to which a mediator always or never uses them that comments on flexibility. Another comment in this regard came from a lawyer- mediator with extensive background in both civil and non-civil mediation:

I never use ground rules... Instead. I usually start out with a monologue explaining that this is going to be a difficult lime and that it is going to be very challenging to hear some of what you are each going to hear, but that you need to hear it. I don't sec the value in laying down a set of arbitrary rules. regardless of how much emotion I anticipate in a given dynamic. l'd rather use the caucus to defuse a siluation if someone flies off the handle.

One of the components of the mediation process that we discussed in the interviews was that of disputant "storytelling," a concept also referred to in the literature as opening statements. As it sounds, this is a phase of the standard mediation model wherein each party tells his or her "story" in turn, composed of their view of the dispute, including their position on the issues and, sometimes, their interests or what they otherwise hope to accomplish by participating in the mediation process. The interview outline that I designed included some specific discussion surrounding the way in which the mediator uses or doesn't use the component of storytelling, and the data that emerged from these discussions comments on mediator conceptions of flexibility. For example, one mediator explained: 
I always use the storyelling right after my opening statement as the mediator. In mandatory mediation cases. I always ask the plaintiff to go first, provided no one objects. After all, the plaintiff is the one who brought the matter to court; let's hear what they have to say! I always give them their opening and then, depending on the case, ask them to go through the claim and explain it. Then $]$ repeat this process with the defendant.

I found it interesting to note in the above comment the "nod" that the mediator gives to flexibility with "I always ask the plaintiff to go first, provided no one objects." This, what I will call the "negative option" approach, is one that was commonly repeated throughout the interviews when discussing process components and models. Another mediator similarly stated that he always "asks to hear first from the plaintiff. Then I ask if anybody objects to this ... they never do!" I suspect that these mediators recognize a certain benefit in allowing the parties to design the process and its components, yet in practice do not give much credence to that objective. Perhaps there is a recognition that some matters are best dictated for the parties rather than arriving at each decision on a consensual basis. As another mediator noted:

It's fair to say that in the roster cases, I always ask the plaintiff to go first. provided that no one objects. I don'I want to appear to controlling, though ... ha. So then I invite them to change the order if they wish. I must tell you, it's never happened in all the mediations I have done! It's a cultural thing; the defendant is never going to elect to go first ... it's just part of our litigation mindset.

Finally, when asked to discuss the models that they use, particularly in the mandatory mediation context, a number of mediators responded in a way that clearly articulated their practice of implementing one, single model in each mediation session. Again, as phenomenography is not interested in evaluating the accuracy or "reality" of the conception, it is chiefly of interest to my analysis that these mediators expressed themselves in a way which suggested their perceived practice of implementing only one model with a standard set of linear components, regardless of how they actually practice.

This is akin to my analysis surrounding the denied centrality of settlement as a measure of success. A contextual analysis allows the researcher to consider the various ways, both spoken and unspoken, that respondents express their perceptions. The challenge lies in accurately interpreting the data so as to not, on the one hand, accept at face value the stated views alone, but to also avoid the pitfall of continually trying to ascertain the "truth" on the assumption that the views as expressed do not so qualify. As one mediator noted when discussing the way in which he manages the mediation process:

I always use a standard model. It's easier and clearer that way. And it works. In roster cases, I do an introduction; I set the scene. I have an elaborate agreement to mediate that is signed in advance. I introduce and talk about myself. I describe my role and the parties' role, in that order. I stop and ask if there are questions or comments. Out of courtesy, 1 suppose. Then 1 turn to counsel and ask for a brief summary, plaintiffs first.

This same mediator described his approach to his community mediation practice: 
The model I use in community mediation is different, but equally clear. It consists of opening statement by myself, followed by party storytelling, dialoguing and problem solving. It is like following a formula ... a recipe.

Although not asked directly about flexibility, another mediator, who is also a practising lawyer, attributed his inflexibility to having had legal training, noting:

\begin{abstract}
As a lawyer, I am quite rigid about structure. I think in boxes. But I believe that I am of much greater benefit if I can bring myself to think outside the box, using creativity and flexibility. I mean, we are trying to get parties to think outside the box, so we need to set the right tone here! I just doesn't come easily for lawyers. Although I don't know for sure, I suspect that mediators who don't have a legal background have a much easier time of being flexible and in thinking creatively and facilitatively.
\end{abstract}

I was left with the distinct sense that a great number of the mediators in my sample were more apt to be guided by a standardized model of mediation, and standardized mini-models for each of the various set components of that process. While we will see below some of the comments representative of mediators who shared a different approach to flexibility, I suggest that the overwhelming majority implemented a far more fixed procedure.

\title{
F2: "I tend to start with my standard model, but then go where the situation and the dynamics lead me"
}

The next two clusters of conceptions were more difficult to distinguish from each other, as they essentially occupy spaces along a continuum that are difficult to delineate. What we see in these groups is an increasing degree of process flexibility as articulated by the mediators who were interviewed. Whether a specific comment more accurately falls into F2 or F3 is admittedly an inexact assessment, but I have created the two classifications to indicate a growing degree of flexibility.

To describe the following group of conceptualizations offered by mediators, I would suggest that they indicate a view that while there is a clear model of mediation, complete with certain components, that is used as a starting point, this model is only implemented as long as it is useful and mediators quickly abandon it, as the situation dictates, in favour of a more useful approach. The fine distinction between this set of view and those that follow is that I suggest the F3 grouping contains comments that suggest that there really is no workable "starting point" model and that each situation is unique, requiring a totally different approach that is customized to the specifics and needs of that dynamic.

When talking about the use of caucus, a number of mediators intimated that they don't always use caucus, choosing it only in certain circumstances, be that high emotion, standstill on the issues, or otherwise. As one mediator stated:

Using or not using caucus depends on a bunch of things, but mainly on whether or not I see a possibility of movement towards settlement. If my reading of the case is that no one is going to settle today, then we have a pretty short meeting. But, if I think the parties just need to spend some time thinking things over, and that settlement is possible, then I often will use the caucus. 


\title{
Another said:
}

\begin{abstract}
You know, despite what all the trainers and the writers say, I don't like using caucus. It is so hard to be fair and balance the time spent with each party in caucus, so you are always trying to confirm that you aren't favouring someone. Also, you enter a different role in caucus. You are doing shuttle diplomacy type mediation, and you are taking away power from the parties to make their own decision as somehow you become part of that process in caucus. Yet, I know that sometimes you have to use caucus for a number of good reasons. Intense emotion, a lack of information or sometimes the parties ask for it specifically. Either way, even if I do use the caucus, I try to get back into joint session as soon as possible; the caucus is only a temporary intervention. It is not supposed to be a progressive stage in the process.
\end{abstract}

There were a number of comments made in a similar vein, describing the appropriate use of caucus and its triggers. While that was interesting content in itself, I found the greater interest lay in analyzing these comments for what they said about mediator conceptions of flexibility in the mediation process. I found similar sentiments expressed in discussing the use of ground rules for establishing expectations at the outset of the mediation session. While some either always or never used them as indicated above in the FI comments, a number of mediators suggested that ground rules, both their establishment and their enforcement, need to be handled with a certain degree of discretionary application. Again, this has bearing on the issue of flexibility. As one mediator described his approach to ground rules:

\footnotetext{
I always try to remember that it is their process. I'll manage it once they decide on what the process is going to look like and what the basic rules are. There is absolutely no point in setting rules and either strictly enforcing them or not enforcing them, automatically. You have to have some control, but far more importantly. you have to excreise that control with some discretion... When it comes to enforcing the ground rules, I am very careful. If I have to keep interrupting to call someone, it tends to interfere with the process. If they are engaging each other and we are getting some "cross talk," I let it go usually. But if it gets nasty and hostile. 1 generally stop it or call a break if things get really hot.
}

For the mediators who statements fall into this section, there is clearly a recognition that while the mediation model does provide a framework, it can easily be broken down into a set of skills and interventions to be used as required. By contrast, mediators whose statements fall into the next grouping might deny, had they been asked, the existence of any standard mediation model, even as a starting point in the process.

\section{F3: "We all study this standard model, but you know what? It really doesn't apply. You use what works in a given situation"}

In this highly contextual approach to the mediation process, mediators who comments fell into this grouping, while far less common than the others, displayed an approach to mediation that was entirely situational, contextual and party-driven. When asked about what model(s) of mediation she used, one mediator explained:

I start with who I am. But that is about where my standard approach ends! I give my view of what this is about and may even suggest some use ful ways to think about appronching this conflict ... but once you get past that, it is just whatever works. I tend to be more facilitative and part of that is just my personality.... Onee the mediation begins to proceed, you build lhis web of connections and I just sort of nudge things along ... I spend 
all of my time reading the parties for signs of where they are at and trying to use that information to figure out what is the next best step.

Another mediator applied this flexibility to the distinctions between different types of mediation cases:

Perhaps in community mediation. you can use a pretty regular standard model. I don't know, but I have that sense. But there is no way you can be standardized in any other type of mediation. While I'm not a transformative mediator, I do believe in some of the concepts of transformative mediation, and 1 think a good mediator has to use a whole bunch of different approaches and tools, in terms of Riskin's grid. I use what works, and I will adjust that accordingly. While counsel in a big business dispute don't want anything that approaches a transformative model, I give them something that will make sense to them and give me some credibility. It's very different in family mediations but equally important to be guided by the context.

In discussing his use of ground rules, one mediator noted similar views to the above:

You know. I don' i always use ground rules. It depends on the group. Some would feel I was talking to them like five year olds if I explained that everyone has to "play nice." In other cases, you know before you even met the people that you are going to need to have some boundaries set. In those cases, though, I negotiate the ground rules with the parties. I ask them what they think would be appropriate rules for civil conversation. Often, I'll get back from them, "What do you think?" I might make suggestions, but hopefully ['Il get everyone to buy into working out four or five acceptable rules. Again, it totally depends on the people and the dispute.

This group is representative of what I suggest is the most flexible approach to the mediation process. While there is no suggestion that this is more or less appropriate, 1 do think it noteworthy to comment that mediation literature is quite unequivocal in its highlighting of flexibility as one of the key characteristics of an effective mediator. I also find it interesting to note that for the mediators whose comments appeared to indicate less flexibility in the process, this view was often qualified with a focus on the importance of certainty and knowledge when it came to expectations respecting process. I suggest there was a recognition that ascribing to a firm and singular model of mediation was not in keeping with the theoretical views of mediator flexibility, despite the fact that mediation training invariably teaches an established linear process model.

\section{b. Conceptions of Mediator Intervention and Management}

If the above concept of flexibility can be reduced to mediator views on managing the process itself, this section might be described as being about the way in which mediators manage the participants. While there is undoubtedly some overlap in a mediator's conceptions respecting process flexibility and process management, I think the distinctions are worth highlighting.

The following three groupings of mediator statements are placed along a continuum ranging from views that suggest the mediator as the key controller of the process and parties, through to a view of mediation that sees the parties as controlling not only the outcome of the process, but the various elements of the process itself. While this does have overtones of 
flexibility measures, it goes beyond flexibility to suggest an accountability and responsibility for the shape of the process and, as such, the resulting path followed by the conflict.

Again, as with the section on flexibility, I didn't ask mediators directly what they thought about mediator interventions and management techniques. I was concemed this would lead to me being given the "right answer," as each mediator perceived it to be. This concern was especially key in this section, given the wide-ranging theoretical debate among practitioners and scholars alike regarding the appropriateness of mediator interventions in the process.

Instead, I have used an inferential analysis to consider data emerging from statements given in discussing various aspects of mediation and using that analysis to suggest groupings of statements according to the relative views they illustrate respecting mediator interventions and process management.

\section{MI: "It is my process, so I set the rules. I decide what they are and I enforce them as I see fit in order to manage the process effectively"}

The first grouping of comments under this heading illustrate, in my view, a conception of the mediator role in mediation that sees mediators as the empowered process managers who retain ultimate control and authority for both the process of mediation and, in some cases, its outcomes. While sometimes these mediators make comments that suggest that they try to establish a façade of empowering the parties in designing and implementing the process, they are often quite clear in their intention to retain control through the use of various controlling interventions. For example, as one mediator noted, indicating his automatic use of the caucus:

The mediation is about the parties and the lawyers, so I give them what they want ... the caucus. Plus, it is far easier to mediate effectively when people are not in the same room. You can control what is said, you can talk to people more easily and more openly. You can be more honest, both as a mediator and as a party. They tell you things they would NEVER tell the other party and you can do the same. You end up being the only one who really knows what is going on and sometimes that's a good thing!

Another mediator noted:

I have developed an interesting and novel, I think, use of the caucus. In a recent mediation, I realized that because I was the only one hearing all sides in the caucus, I was able to frame and reframe peoples' statements in a way that I knew the other side would buy into. I did this shutlle reframing using the caucus to come up with the frames that were at least palatable and acceplable to the other side. They didn' I know I was doing that, but it helped me to control the process and encouraged settlement or at least common ground.

When asked about the process framework that he implemented in his mediations, one mediator described what he called a "therapeutic family model" for conducting mediations between separating and divorcing spouses. Some interesting views about mediation management emerged from this discussion, including the following comment:

Traditional mediation notions of empowerment, self-determination and neutrality are inconsistent with this [therapeutic family] model. Rather, the central issue is one of professional authority. While perhaps selfdetermination and empowerment may apply to a limited extent, the mediator must continue to hold procedural 
control at all times, however this is achieved. The power and authority that the mediator has adheres in the role; it comes from the parties, they insist that I have it because they understand they are unable to be in control of themselves, the conflict and its resolution.

In discussing the approach to using ground rules, the following statement made by one of the respondent mediators is quite reflective of views expressed by several others, views that provide insight into those mediators' conceptions respecting mediator interventions and management of the mediation process:

I used to put a lot of energy into establishing consensual ground rules. Now I don 't worry about consensus: let's be honest, il's their conflict but it's my process. I see establishing ground rules as simply "setting the table." In terms of enforcement, I enforce any breached rules immediately, in a friendly but deadly firm manner.

In a similar tone, another mediator explained:

I impose ground rules without any input whatsocver from the participants. That is part of my control in both managing the process and, mote importantly, in establishing and building my own credibility and authority as the process manager.

Perhaps not surprisingly, many of the comments that fall into this spot on the continuum of mediator process management were made by the same group of mediators who articulated views of flexibility contained in the F1 grouping above; in other words, mediators who tended to view the mediation process as one with a fairly structured format to be applied universally, regardless of the conflict or party contextual specifics. As will be seen in the next portion of this analysis that proposes informal categorical groupings of mediators according to all of the factors considered, I suggest at this point that other parallels will be seen between the mediators who tend to exert more control in a standardized, inflexible process and other descriptive collections discussed above.

\section{M2: "The irony is that I try to maximize the power I can gather} early on in the process, but my hope is always that I won't need to use that power"

As with the section considering conceptions of flexibility in the mediation process, the expressed conceptions respecting interventions and management approaches have been delineated along a rough continuum, ranging from a view that suggests greater interventions and "more" management through to a view consistent with fewer interventions and less management of the process. As above, I suggest that while the exact location of some of the spots along this continuum, held by various mediator comments and inferences, may be somewhat inexact or debatable, this exercise is not intended to be exact. Rather, the objective is to illustrate the range of views espoused by mediators ranging from greater control over the process to lesser control. The exact stages in the range are far less important than is illustrating the range itself.

This grouping of comments and inferences along the continuum is intended to illustrate a view of the use of mediator interventions and management tecliniques characterized by less 
mediator involvement in the process. Rather than mediators suggesting a role that uses powerful interventionist techniques to firmly manage the process as was discussed by some of the respondents in the preceding grouping, the statements in this section reflect a view of mediation that sees the mediator as a more facilitative player in the process management role.

One mediator clearly distinguished her approach to interventions, comparing her family law approach to the one she adopts when conducting mandatory cases for the roster:

My approach to managing the process is very dependent on the nature of the conflict.... When I do roster cases, which are often personal injury disputes, it is all about money. Relationships don't matter to parties, so I work hard to understand the facts of the case instead ... I take a highly analytical and fact-based approach and use interventions that encourage parties lo move towards compromise without much focus on the future.... But in a co-parenting situation where the parents are divorcing, the relationship is central so the kinds of intervention techniques that I use there are very different ... I try to open and to continue with a constant focus on the future relationship. Couples who are splitting up often don't understand how much contact they are going to need to have in order to deal with their children... I use key interventions in a way that allows me to establish rapport with the parties, and some degree of common understanding between them.

In discussing the role of mediator neutrality with one respondent, conceptions related to mediator interventions and process management emerged:

I strive to be neutral, but let's be hones1, it isn't always possible ... we each have our own sense of justice and standards that we bring to the process; our own sense of how we would like it to be resolved. I try to identify these judgments as I make them, to take them out and examine them, and then I try to let go of them and ensure that they don't impact on my behaviour as a neutral.

That is not to say that I don't try to move the process in a certain direction sometimes. I have to choose when to be silent or when to speak up and play devil's advocate a little bit. Maybe I see one side being what I perceive to be unfair in their approach... I guess I have to admit that when and how I employ interventions is often dictated by my wish to move the parties towards a position which accords with my own sense of justice, and perhaps that reflects on my own neutrality.

Interventions are not limited to being used to direct the parties. As one mediator put it:

Not always, but sometimes I have to do some mediation with the lawyers. I mean, I don't announce that I am now going to use interventions with them, so they aren' I necessarily aware of it, but I have come to appreciate that it is crucial to have the lawyers in a place where they won't hurt the momentum of the case, especially if it begins to move towards a resolution. So $l$ use some of my tools to manage the lawyers in a gentle way.

Again, we see a correlation here between those mediators whose comments fall into the midpoint in terms of flexibility, and those who articulate conceptions of various components of mediation that suggest an attitude towards process management that is more responsive to parties and less driven by the mediator himself. 


\title{
M3: "I negotiate everything. I ask for input and then we all decide together on the best approaches to the matters as they arise"
}

What distinguishes comments in this grouping from those in the previous one is a greater degree of focus on the parties as the chief architects of the process and outcomes of mediation. While those mediators in this grouping still recognize the mediator's role as facilitating the process to some extent, they clearly identify the parties (and in some cases, the lawyers) as primary mangers of the process. As a result, these mediators claim to use less intervention in managing the agenda of the mediation session and to delegate more process direction to the parties. In discussing power in general, one mediator raised the issue of process control, noting:

\begin{abstract}
A mediator only has as much control over the process as the parties and lawyers give you. It is always given by the parties, and sometimes isn't given at all. I had one mediation where counsel totally took over the process and cut me out of it, but you know what? It was working, so I sat back and let them run with it.... I thought a lot about that session aftenwards, but l've realized that my sense of satisfaction and my personal self-esteem doesn't come from whether or not I think the parties think I am strong and in control. It was a very interesting reflection.
\end{abstract}

Another mediator spoke about her use of the caucus, with its implications for managing the process:

I'm not a big fan of the caucus because it really gives me too much secret control. I don't always use it, especially if $I$ can avoid it. Yet, often the separation occurs without me initiating it if, for example, the client looks at the lawyer and says "we need to lalk" ... in my non-personal injury cases, I can avoid caucus more often and probably only use it in 70 percent of my cascs. Often, happily, we can accomplish a resolution or at least an improvement in the situation, while working together in the whole.

When discussing mediator neutrality and the concept of levelling the playing field when a mediator considers it to be unbalanced, one mediator made the following comments that I suggest also reflect on her views respecting interventions and process management:

Levelling the playing field all comes back to neutrality and my views on it. Just because I think a lawyer is incompetent doesn' 1 mean that he is. Nope. ORen I will come away thinking, for example, that a lawyer was incredibly weak and really hurt her client's case, but I can't play God. It all comes down to how you see the power ... sometimes a single employee may be the one holding all the power against a big corporation, despite what you might assume. You definitely have to be careful using interventions to manage your sense of power and faimess.

In a very similar manner, another mediator described a mediation he had conducted between an unsophisticated landlord and some young professional tenants who were represented by counsel:

One of the dangers of power balancing is that you might make a mistake and pick the wrong party to prop up! Sometimes a party who appears weaker is in fact stronger [relating the landlord-tenant case].... As it turned out, the apparently weaker party in fact held the most power because he was approaching this as a matter of personal honour. His sense of integrity empowered him, so he didn't need my help, even if I had been inclined 
to give it. You have to be very careful if you decide to level a playing field and make sure you accurately read the field!

Another mediator highlighted the issue of parties specifically asking for guidance from the mediator, despite the presence of lawyers, in how to proceed from a given point. As this mediator noted:

When parties ask me what we should do next, 1 remind them of my role, which 1 described at the beginning in my introduction. I remind them that I said then that my role is to facilitate and their role is to work out a solution. Instead of using that power to direct the process when the parties essentially hand it over to me, I try to redirect the power back to them. It is their role and their duly to work at resolving their conflict. It is not up to me to manage.

These conceptions of mediator control over the process emerged from a wide variety of data on various interview topics. Process management can range from what one respondent described as "subtle" through the range to what another called "heavy duty control." Regardless of the conceptions expressed regarding mediation process measures, it was clear that the level of management at every stage in the process was one of conscious judgment and choice by the mediator. In some cases, a mediator who claimed to be non-interventionist when it came to the use of caucus, offered an example using ground rules where the rules were enforced in a highly disruptive way in order to get a mediation back on track when the mediator perceived it to be losing momentum. The dimension of choice is a central one to mediator behaviours, or at least to conceptions of those behaviours.

\section{B. Categorical Tueories of Mediation}

The next step in this phenomenographic approach was to propose categories for grouping the various conceptions offered by mediators on a wide range of topics, recognizing that mediators do not hold their conceptions of these elements of mediation as separate and distinct. Rather, these views must, once considered in isolation, be recognized as functioning as part of a larger overarching conceptualization of mediation in which the threads of philosophy, goal, process and role are interwoven into a single fabric.

As noted, the methodological objective of phenomenography is to suggest categories of conceptualizations of a group of people about a specific phenomenon. Usually, phenomenography does not consider any connections or correlations between conceptions of different phenomena or between, for example, demographic data of the group of people being studied and their conceptions. However, I suggest that certain conceptions, at least in this study, are closely connected to other conceptions in a way that combines to create a conceptual paradigm. It is, I would suggest, the relationship between the conceptions of various "parts" that combine to create the "whole." By considering the interconnection within and between the conceptions that I have discussed above, I have proposed three categories of mediator conceptions of mediation.

While these categories are admittedly exploratory and would benefit from further testing with a larger sample, I suggest that they accurately represent three distinct understandings of the reality of mediation as held by a group of mediators practising within the OMMP. As 
phenomenography is intended, at its most basic, to "investigate the qualitatively different ways in which people experience or think about various phenomena," ${ }^{* 1}$ I suggest that the categories resulting from my study provide exactly that; different conceptualizations of the reality of mediation as practised within the context of a court-connected, mandatory model.

In considering the categories below, I have repeatedly asked the question, would other researchers find the same conceptions and categories if they conducted the same study and if similar data was generated? Phenomenography provides the following answer: replicability is not reasonable to expect with the phenomenographic method.

The original finding of the categories of description is a form of discovery, and discoveries do not have to be replicable. On the other hand, once the categories have been found, it must be possible to reach a high degree of intersubjective agreement concerning their presence or absence if other researchers are to be able to use them. Structurally, the distinction I draw here is similar to that between inventing an experiment and carrying it out. Nobody would require different researchers independently to invent the same experiment. Once it has been invented, however, it should be carried out with similar results even in different places by different researclicrs. $^{42}$

With this in mind, the mediators interviewed in this study offered their views and conceptualizations of a variety of phenomena related to the philosophy, practice and process of mediation. From these clusters of conceptions, I have constructed some informal theories, or categories, of mediator conceptions of mediation. These theories emerged from the data generated by the mediators themselves, in traditional grounded theory approach. Yet it should be noted that this method of generalizing is highly inductive in nature. As Barney Glaser and Anselm Strauss describe in The Discovery of Grounded Theory,

[t]o make theoretical sense of so much diversity in his data, the analyst is forced to develop ideas on a level of generality higher in conceptual abstraction than the qualitative material being analyzed. He is forced to bring out underlying uniformities and diversities, and to use more abstract concepts to account for differenecs in the data. $^{43}$

Glaser and Strauss proceed to explain that working from raw data, as in this case, will lead to the emergence of a substantive theory. In other words, a theory for the substantive area of mediator conceptions of mediation will be achieved. Had I been analyzing, instead, a series of these substantive theories on this topic, generated by various researchers, the resulting theory is more aptly named a formal theory, as is an overarching map for understanding a broader conceptual area. I suggest that the following categories take into consideration various interrelated clusters of mediator conceptualizations of mediation and in doing so, posit an informal substantive theory in this area, suggesting a generalized understanding of the way in which mediators conceive of mediation.

$4 \quad$ Marton, supra note 25 al 31.

Ibid. at 35.

Barney G. Glaser \& Anselm L. Strauss, The Discovery of Grounded The ory: Strategies for Qualitative Research (New York: Aldine de Gruyter, 1967) at 114 [emphasis added]. 
Certainly, clear patterns emerged among the various conceptions, some of which are identified in the sections above. For example, many mediators who offered perceptions of mediator philosophies respecting success in the $S 3$ grouping also expressed views of the goals of the OMMP in the substantively related GI category. Although these pattems were noted frequently enough to warrant their grouping into modules or units, they were not universal. Some mediators who held the $S 1$ philosophy of mediation expressed views respecting the OMMP program goals that fell into the G2 articulation.

This repeated patterning that, fell short of universality, served to encourage the increasing abstraction, noted by Glaser and Strauss, of the resulting proposed categories articulated below. As each connection between the data was either present or absent, the resulting substantive theory respecting categorization of mediator conceptions needed to be further abstracted in order to include all permutations of the data. With that in mind, I suggest the following categorical organization of mediators' conceptions of mediation.

\section{THE UTILITARIAN THEORY OF MEDIATION}

\section{Conceptions:}

S3: "Mediation is clearly about settling cases!"

G1: "The OMMP encourages early settlement, nothing more and nothing less."

F1: "What I bring is a process consistency that can be relied upon by everyone in the room."

MI: "It is my process, so I set the rules. I decide what they are and I enforce them as I see fit in order to manage the process more effectively."

Mediators who expressed the views captured by this category tend to conceive of mediation with a highly pragmatic orientation, seeing it as a technique for resolving litigated claims rather than as a paradigmatic approach to conflict. Mediators in this category commonly reduce conflict to distributive disputes that require from each party varying degrees of compromise in order to resolve.

Regarding correlations between conceptions that led to the emergence of this category from the interview data, mediators in this group clearly conceptualize of the OMMP as a program focused on settling cases and see themselves as successful if they are able to achieve that goal. Of note, this category of mediators is populated almost exclusively by respondents who also hold a background in legal education and practice. That is not to say that some lawyer-mediators do not ascribe to a different theory of mediator conceptions, as some are included in the following two categories as well; however, lawyer-mediators clearly dominate this category.

In terms of conceptualizing the process of mediation, especially in terms of its flexibility and the management techniques employed by the mediators, this category of practitioners see the process as highly regulated and fairly inflexible. In terms of their role in managing this 
process, mediators in this category conceptualize a mediator-driven model whereby they retain the greater portion of the power and use that to control the process and guide it what they view to be an appropriate direction - usually towards settlement if at all possible.

\section{THE FUNCTIONAL/RESPONSIVE THEORY OF MEDIATION}

Conceptions:

S2: "Mediation is about helping people look realistically at their options and strategies."

G2: "The program is there to help people understand their interests and their motivations in terms of conflict."

F2: "I tend to start with my standard model, but then go where the situation and dynamics lead me."

M2: "The irony is that I try to maximize the power I can gather early on in the process, but my hope is always that I won't need to use that power."

Mediators who fall into this category often explicitly recognize some of the pragmatic concepts of mediation expressed above but, in addition to this, commonly articulate a function of mediation that goes beyond the settlement of the dispute. That "function" can vary; it may be to educate the parties about themselves, their opponents or the conflict. Some articulated a function of mediation to be the creation of an atmosphere where parties could feel comfortable exploring alternatives and options, be they settlement-oriented or otherwise.

Notably, this category of mediator conceptions begins to move away from the notion of mediation as a tool or technique to be applied in isolation, and begins to develop a conceptualization of mediation as a paradigm or framework for approaching conflict more generally. This category does not entirely abandon the pragmatic view of mediation as a useful tool, but softens that view by including some other related benefits of the process. In some cases, mediators seemed to suggest that these side benefits were intended as part of mediation's value; in other cases, the benefits appeared to be understood as inadvertent.

Mediators included in this category tend to have expressed a view of mediation that encapsulates a greater flexibility in both the process and in the role of the mediator as process manager. It marks a far more contextual approach to mediation whereby the mediator tailors her approach and expectations to factors external to her own views; namely, the objectives of the parties, her perception of the dynamics of the dispute and the developing evolution of the conflict itself as it encounters the mediation process. 


\section{THE RELATIONAl. TIIEORY OF MEDIATION}

\section{Conceptions:}

S1: "Mediation is successful if the mediator sets an example of how to handle conflict."

G3: "The OMMP, while not intended to empower people, does give parties a chance to get their voices back and to use them."

F3: "We all study this standard model, but you know what? You use what works in a given situation."

M3: "I negotiate everything. I ask for input and then we all decide together on the best approaches to the matters as they arise."

This category of mediator conceptions represents the closest point to a transformative model that was expressed by mediators interviewed in this sample. ${ }^{44}$ To be clear, this theory of mediation remains far removed from the characteristics of what has traditionally been labelled the transformative approach, but it is moving towards that end of the continuum.

Many of the mediators included in this category articulated at some point in our interviews the notion of mediation as "magic" in terms of its ability as a process, as a mindset really, to overcome extremely divided relationships and deeply entrenched conflict. However, it should be noted that none of these mediators suggested that the potential for such magic exists within the bounds of the mandatory mediation scheme being considered in this study, the OMMP. In fact, mediators took some pains to distinguish that while they believed mediation had incredible potential for "magic," such potential was either significantly or entirely eliminated by the realities of the OMMP.

In particular, they pointed to the inability of roster mediators to work with individual parties in a "case development" phase of the mediation, prior to the formal session. They also noted the reality that the majority of OMMP cases do not involved long-term or ongoing relationships between parties, a characteristic that does not support the relational focus of transformative mediation. Further, these medjators pointed to the inadequacy of the set, threehour mediation sessions in the OMMP model that precluded any meaningful excavation of the parties' respective needs and interests.

That having been said, these mediators articulated a conception of mediation that demonstrated an ability to completely rearrange the conflicted relationship between parties and assist them in empowering themselves to overcome their disputes and improve their interaction dynamics on a going-forward basis. Clearly, these mediators viewed their goal as mediators to assist parties in understanding themselves and their conflicts better. And they

"+ For a discussion of the transformative model, see Robert A. Barucli Bush \& Joseph P. Folger, "Changing Pcople, Not Just Situations: A Transformative View of Conflict and Mediation" in The Promise of Mediation: Responding to Confict Through Empowerment and Recognition (San Francisco: Jossey-Bass, 1994) at 81. 
recognized the OMMP as having as one of its objectives the increased participation of disputants in the resolution of their own disputes. What varied among the mediators in this category was the way in which they prioritized these goals, of both the mediators and the OMMP. For some, the relational objectives of the program and its mediators seemed to be primary, with settlement goals holding secondary position. For others, this ordering was reversed. In any event, there was a strong recognition of the duality of objectives of both the program and the mediators, encompassing the pragmatic ends of settlement and the "Joftier" aspirations of improved relationships, self-determination and personal empowerment.

In terms of the conceptions of the mediation process that made up this category, we see views that claim a highly flexible, responsive approach to mediation and one that is consciously party-driven. Mediators describe a far more facilitative approach in this category, although some still do recognize their responsibility to sometimes nudge the process when it seems to have stalled. These mediators claim to engage in strongly consensual decisionmaking, from setting the ground rules right down the line to negotiating when and how a caucus will be implemented, if at all.

Rather than seeing mediation as a technique or tool, I would suggest that these mediators see mediation as a model for approaching conflict, the "tools" of which are a number of flexible steps or interventions that may or may not be used, depending on the unique context of the dispute at hand.

\section{CONCLUSIONS}

It should be noted that even these mediators who are located towards the transformative end of mediation theory are in no way at that end itself. There was little if any talk of the quasi-religious "promise" of mediation as a tool for achieving a paradigmatic shift akin to a new world order. While clearly scholars have identified such an approach to mediation, I did not find that among this sample, except as noted above, to contrast the inability of the OMMP program to provide an environment for such transformation to the extent that other non-OMMP models do. So while these mediators discussed at some length the ability of mediation to impact positively on relationships, be that in the community setting or in dealing with divorce conflict, that ability was clearly not available through the OMMP.

The mediators participating in this study expressed a great diversity of conceptions respecting the mediation process generally and its various specific components, goals and philosophies. The interrelationship between the conceptions surrounding various topics indicated compelling patterns of conceptualization, from which emerged these three natural categories of mediators' views. Using a "clustering" approach, significant patterns were seen, for example, among mediators who espoused one view of mediation flexibility and a corresponding view of the goals of Ontario's mandatory mediation model. The next step was to consider the application of these categories to mediators' conceptions of power in the mediation process. 


\section{Findings Il: Mediators' Conceptions of POWER in Mediation}

There exist a variety of lenses through which to consider mediator power and how it impacts on the mediation process. Throughout the formation of my dissertation, I developed some distinct perspectives on power analysis that particularly interested me. Having identified a scarcity of empirical research on mediator power, reducing that gap became the goal.

During the interviews conducted for this study, two enduring themes surrounding power emerged from the data; namely, the philosophy of power and the actual use of power. These thematic frameworks, when combined, served to capture the vast majority of the views articulated by mediators surrounding the presence of mediator power in mediation. Under the admittedly ambiguous heading of "philosophy," I have included mediator conceptions respecting ideas such as the definition and sources of mediator power. It should be noted here that the working definitions of power adopted by the interview respondents belong to them; they tended not to encompass some of the more recent, contextual theories of power in conflict resolution and in fact, were generally quite traditional in assuming classical views of power as described below.

The second grouping, conceptions of the utilization of power, evidences the extent to which the subject mediators of this sample expressed an interest in how mediators implement power. Some respondents reported on the manner in which power is used, while others focused their comments on the normative approach of how power should be used by mediators. Despite this difference in vantage points, I found their comments in this area to be highly instructional in detailing and elaborating upon the three categorical theories of mediation proposed in the previous section.

The next step was to consider groupings of mediator conceptualizations surrounding (a) the philosophy of power as it pertains to the mediator and (b) the role of mediator power. Then, the three categorical theories of mediation proposed above were applied using the data that emerged around these aspects of mediator power. I propose the resulting categorical "models" of mediation.

\section{A. Mediator CONCEPTIONS OF MEdiator POWER IN MEDIATION}

\section{CONCEPTIONS OF THE PhILOSOPHy OF POWER}

One of the scheduled topics of discussion for the interviews was mediator power. We also discussed the power of participants in the mediation process, but there was a distinct interest on behalf of the mediators sampled in defining, sourcing and discussing specifically the use of mediator power. In terms of what I have gathered under the heading of "philosophy of power," a variety of comments are included that express views of both the definitional nature of power in mediation and the nature of its sources.

I found an interesting correlation between the comments of these subject mediators and the frameworks of power considered in conflict theory literature and, more generally, in conventional power theories. While I did not explicitly suggest any specific frameworks of 
power, some of the classical conceptualizations emerged, such as, for example, the ability to either impose one's will (Weber), set the agenda (pluralists) or shape the preferences of those with interests perceived as conflicting with one's own (Lukes). The mediators, and hence the emergent data in this grouping, illustrated distinct affiliations with these approaches. It should be noted that these theoretical approaches to power are not alternatives, but rather are cumulative. I should also note that not one of the mediators suggested any of the more current typologies of power, for example, the relational models of power, rooting their comments, rather, in far more conventional frameworks.

What emerged was the first group viewing power as the ability to impose one's will on another through the use of subject expertise. The second category assumes an adoption of this definition, plus the idea that power also encompasses the ability to manage the issue agenda. Finally, the third approach to power encapsulates the two preceding frameworks and adds to those with the idea that power also includes the capacity for shaping preferences and interests. Considering the data in context, the following conceptualizations of a philosophy of power are most representative of the ideas expressed by the sample of mediators interviewed.

\section{P1: "Power comes from being an expert in the subject of the conflict"}

A number of the mediators interviewed expressed the notion that mediator power comes from the subject knowledge demonstrated by the mediator. This conception of power was often expressed by mediators who had also trained and practised as lawyers, implying that the value they bring to mediation lies in their ability to understand the conflict in terms of its legal analysis. This perception of power most directly connects to the Weberian definition of power as the ability to compel another actor to behave in a way that he would not otherwise behave.

By demonstrating an understanding of the legal merits of the two positions being advanced by the parties, a mediator with this view of power perceives her own role to be to advise parties on the relative strength of their competing claims and to suggest the likely outcome of the continued litigation of those claims, should they be unable to settle the matter through mediation. As one mediator noted:

\footnotetext{
Mediators have a huge amount of power and it comes from sociely's experience and the faet that people are looking for the law to settle their disputes. Parties are actually looking for the mediator to tell them what to do and who has the better legal case. Even in the mandatory mediation program, there are implications in the caucus and they will ask, "what do you think?" or "what should I do?" I have power because I have the answers to some of these questions.
}

Similarly, another mediator commented:

Mediators have the most power. We get it from moral suasion and especially from out knowledge about the dispute. We gain power from the more stuff we can dig up about the dispute; the more information we can gather. Then we fit that into a legal answer and bingo!

Finally, another mediator with a background in law stated: 
I am very conscious of not overestimating my power or my impact that I bring to the mediation session. Then again, it's equally important that I not underestimate my power. There is a balance here that needs to be struck ... my power is drawn from the skill set that I bring to the process. I need to bring some strengths from a facilitative-based perspective, but I think my power especially lies in what I bring from the legal-evaluative perspective with all the skills and knowledge that entails.

In the next category, views of power are considered that focus on a mediator's ability to understand and manage the mediation process. However, in this category of conceptualizations about the philosophy of power, some mediators noted that it came not only from a knowledge of the legal framework of analysis, with its rights-based orientation, but also from an understanding of the legal process. Mediators specifically identified as a source of power their knowledge of civil procedure, of what had already happened in the litigation process for this case and of what lay ahead.

It is difficult to accept this as a source of power solely for the mediator, as surely the lawyers participating in the mediation process carried at least as much if not greater power in this arena. However, it is this knowledge of the litigation process, when coupled with an ability to determine the respective strength of competing claims, that vested the mediator with an air of credibility supporting her ability to direct the mediation in a way that she found to be appropriate. One mediator, trying to explain this synergistic compounding to me, commented as follows:

Sometimes you go into a mediation and you sort of set the stage, just by being who you are. So you show them right off that you know what a statement of claim is in law and that you understand that if they don't settle. they'll be going to discovery. Suddenly, you just have this sense that they see you as this huge repository of knowledge about everything that is inportant to them in this contlict. It isn't just that you know the process, but you know the laws and the statutes affected and you know if they have a good argument. It's the whole package that gives you power and authority.

Certainly, a similar description would apply to the role of a judge conducting a pre-trial settlement conference; yet, it questions whether there should be such a strong correlation between what should arguably be two very distinct roles. In the next grouping of conceptualizations about power, we see a view that explicitly contradicts this one, defining power by where it does not come from: namely, legal knowledge.

\section{P2: “Power isn't about knowing the law; it's from managing the process effectively"}

The vast majority of comments collected under this emergent concept of power did not come from mediators with a shared background in law. While certainly not an absolute distinction, these comments tended to come from mediators who either had a strong background in the social sciences and/or whose practices included a significant amount of mediations outside of the OMMP scheme, most commonly in the context of family conflict.

I suggest that the comments caught in this category lend themselves to a definition in keeping with the pluralist view of power as the ability to set and manage the agenda and in doing so, to keep certain topics from emerging if the one exercising the power anticipates a 
clash of views and positions. ${ }^{\text {4s }}$ As I noted above, it is most appropriate to see these comments respecting power as expanding upon, not replacing, the sense of power as the ability to influence others. With some notable exceptions detailed below, comments that fall into this category arose contextually from a sense that power is "also" about managing the agenda, often in ways that keep certain issues from emerging.

While the comments below are representative of a number of other comments made by mediators that would fall into this collection of data, analyzing these comments in the context of the entire interviews from which they emerged often led to a sense that through managing the process, the mediators had a firm control over some of its outcomes, or at least over the trajectory that would be followed by the dispute during this portion of its route.

I was struck by the sense I had that several of the respondents whose comments fell into this grouping were absorbed to some degree with creating a "niche" power source from which they would not be excluded by their lack of membership in the legal culture shared by so many roster mediators involved in the OMMP. In other words, by claiming that mediator power came from some source other than legal knowledge, they did not disenfranchise themselves from membership in the group of effective and powerful mediators. It could be argued that these respondents suggested this approach to power as an alternative to the previous conception of power as will imposition, rather than in addition to that view. As one mediator explained:

The mediator has a great deal of power and lite lawyers know this, which is why she rarely has to use her power. I guess this power comes from a variety of different places. but mainly it comes from her ability to issue certificates of non-compliance, ${ }^{46}$ and to enforce the ground rules during the process. elc. But most of all, I would say that the mediator has power from her ability to facilitale the process well or not. She controls the process and that gives her a great deal of power.

\section{Another non-lawyer mediator shared similar views:}

As a mediator, your power comes from your role in managing the process. You have the power to select your approach and decide that, for this meeling. I am going to use for example an interest-based or a rights-based approach, and everything that automatically flows from that choice. It is very powerful.

As the impartial person, there is also a strong element of personal power ... the authority of being the mediator, the keeper of the process ... the way in which you carry yourself and conduct the mediation ... and your ability to be authoritative without being authoritarian.

4s For one of the original statements of this view, see Robert A. Dahl, Who Governs? Democracy and Power in an American Ciry (New Haven: Yale Universily Press, 1961). See also, Frederick M. Wirt, Power in the Ciry: Decision Making in San Francisco (Berkelcy: University of California Press, 1974); Paul Schumaker, Critical Pluralism. Democratic Performance, and Community Power (Lawrence: University Press of Kansas, 1991).

45 The Certificate of Non-Compliance is a punitive form issued by mediators pursuant to r. 24.1.10(5) of the Rules of Civil Procedure in Ontario. This is a discretionary measure that medialors may take if one or more parties fail to comply with the various requirements of participating fully in the mandatory mediation session required by the rule. 
Another mediator who had a background in community mediation training expressed a similar conceptualization of mediator power and its sources:

The mediator has lots of power! The greatest power you have is derived from the process and how you manage it. We empower ourselves by establishing a process and then inspiring confidence in that process by ensuring it works effectively.

Power comes not from the cxtent to which you evaluate the positions before you, but from your ensuring that people trust the process and have confidence in yourself and your ability to manage that process. I am most disempowered when I am unable to control the process and, as a result, the parties have no confidence in either me or the process. Those situations never lead to positive results, be that setilement or otherwise.

This was not a view shared only by non-lawyers. In the case of one lawyer-mediator in particular, she and I engaged in a fairly lengthy discussion surrounding sources of mediator power. She had expressed her view earlier in the interview that it was inappropriate for mediators to act as lawyers in any way, so I pressed her somewhat to expand on her views of the sources of her own power as a mediator, if not originating in her identity as a lawyer. She said:

I know what you're thinking; that l'm strong and powerful because l'm a lawyer, right? Well that's not it. I get power from listening and demonstrating that $I$ am listening and that I am hearing what is happening and thinking about what I'm hearing. I don't get power from subject matter expertise. I tell people that I'm a lawyer but I also tell them that I know very little about the subject matter; for example, that l've never practised law in the area of personal injuries. My power surely doesn't come from that.

As another lawyer-mediator explained:

Mediators have a ton of power on a number of different levels and in a number of different spheres. Most importantly, they have power in terms of the process itself. Whether or not they understand the legal niceties doesn't really matter. Despite what we say to our clients in mediation, they look to us for our expertise in how the process will unwind, no matter how facilitative we might seem. Just like I don't want my surgeon asking for my input in designing my heart surgery, clients want me to use my expertise to guide them through the process.

Clearly, this approach to power corresponds well with the institutional role of the mediator, especially in the context of a mandatory scheme such as the OMMP within which all of the respondents participate. When the mediator's role is to move parties through the mediation process, there is arguably an assumption that this will be done in a way that is responsive to the parties' interests and needs. To convert that same role into a method for achieving the mediator's own interests gives concern, especially in a situation where the mediator's goals of settlement may conflict with the interests of those parties. That concern was highlighted for me in the following grouping of conceptualizations. 


\section{P3: "To have power is to set the agenda and then to drive it in the direction you want without showing that you have your own goals"}

The comments represented in this cluster are directly connected to the view of power that sees power, in addition to the ability to impose one's will and control the agenda, as the capacity to shape the preferences and interests of a party perceived as having opposing interests and preferences, so that the party is unaware of their true interests and thereby precludes the emergence of any conflict based on a clash of those interests. This approach to power could be said to most closely correspond to the framework contributed by Steven Lukes, what he refers to as his "three-dimensional" view of power, focusing on the "nondecision making" that occurs in this context.47

Data collected into this grouping was notably less frequently expressed than in the preceding two bands. While frequency is not a concern of phenomenographic method, the comments represented in this section were nonetheless significant enough to demonstrate an emergent view of mediator power.

What distinguishes this selection of comments and others that they represent is the extent to which mediators explicitly identified not only their interests that are often distinct from those of the participant parties and lawyers, but the way in which power was derived from their ability to convince those parties that the parties' interests corresponded to the mediator's interests. In plain terms, these supposedly common interests were most often crystallized into the need to settle the case. The mediators whose comments emerged to create this conception of power often stated their recognition that sometimes a party's interests were supported by an outcome other than settlement; yet, despite this recognition, they expressly used their power to move towards resolving the dispute.

\section{One mediator described his power as follows:}

In private family mediation, I have all the power and I use it to achieve the parties' interests, which most often correspond with my oun. I have the ability to create a common definition of the problem. In roster mediations under the OMMP, I have no power. The power lies entirely with the lawyers; they define the problem, usually not in a way common to all parties. Once we are into the caucus. this power absence is even worse. This is no longer mediation; this is a litigation process.

Until you gain contral over the definition of the problem, you have no ability to exert your authority. In fact. you have no authority whatsoever as it all stems from that ability to shape the problem and how cveryone sees it.

Another respondent seemed to source this power to control parties' interests in the authority vested in the mediator that stems from her identity as a representative of the judicial system:

Mediators have a tremendous amount of power. As the process manager, you can set the agenda to be exactly what you want it to be, and drive that process in the direction you want without showing that you have your 
oun goals. In most cases, parties will let you do it because even though you might say that it's "up to them," they see you as a representative of something else and that something else has power over them.

Another mediator offered insight into the notion of what constitutes "appropriate power" to include this conception of mediator interests:

I will lex whatever power I have, which is a lot, when the lawyers are being unreasonable. I will use what I consider to be appropriate power ... I will use whatever I need to use and however I need to use it to make happen whatever I think needs to happen. I need settlement to happen, so I use my power to get there. I'm a great believer in yelling when it's needed. and I use this skill to test lawyer power because when a lawyer is in the room trying to enforce his power, he is doing it for a number of reasons which may not be on track with what I need to accomplish in the session.

I want to be the guy who makes settlement happen, but it's critical that the parties belicve they made it happen. The parties sure don't want me to be the guy who imposed or forced a settlement. I use appropriate power to get that result.

While there were a variety of comments that accord with this conception of the philosophy of mediator power, the connection could often only be made through piecing together a series of unrelated comments made in a contextual manner, looking at the "whole" rather than the parts in isolation.

As suggested earlier, it strikes me that many of the institutional characteristics of mandatory mediation, at least in Ontario's scheme, enable mediators who are so inclined to operationalize mediator power in a way that achieves their goals and interests, regardless of whether such interests correspond with or diverge from those of the disputants themselves. To mask this exercise of power in such a way that the parties conclude their interests to be common with those of the mediators has interesting implications for the larger question considering the role that mandatory mediation can play as a tool of access to justice.

\section{CONCEPTIONS OF THE UTILIZATION OF POWER}

Another key lens through which to view mediator power is the perceptions of its utilization. Now that we have an idea of what mediators think about the origins and nature of power, how do they claim to use it? Or, how do they claim it should be used? As with the last section, this topic generated a great deal of discussion and variant opinions among the mediators interviewed in this sample.

Given the intensity of my own curiosity surrounding this question, I was extremely conscious during stages of both data collection and analysis to avoid attributing greater focus to these issues than what was credited by the parties themselves. Despite what might have been a tendency or desire to focus heavily in the interviews upon these issues surrounding power, I was careful to avoid signaling this concentration to the respondent mediators in the fear that this would lead to a skewing of results, if not emphasis. As it turned out, a great natural interest in this topic emerged from the data itself, as did some very divergent conceptions relating to the use of mediator power in mediation. 
It was difficult to discern at times whether a mediator was expressing his view of the way in which power is actually used by mediators or his prescriptive sense of how power ought to be appropriately used by mediators. In some of the following comments, this detail is easier to identify than in others. Despite the challenge that this diversity of views posed to grouping ideas in a range of perceptions, 1 am confident that the following conceptions accurately reflect that general points of expression along the continuum of power use.

\section{U1: "Used appropriately, power serves the interests of the parties,} the process and the program"

Although I found many of the mediators' expressions surrounding the utilization of power to be less articulate than those respecting other topics, I attributed this to the complexity of the idea of power, generally, and the challenges inherent in describing its operation.

This group of comments illustrates the view that power is used or should be used as a method of achieving interests, be they the interests of the parties themselves, the OMMP or of the mediator. This sense of the use of power as entirely dependent upon the respective interests was interesting as few mediators who commented in this regard took the next step of suggesting a prioritization of interests, should they clash. The use of power in this category could be described as a means for realizing goals of the various participants in the process and of the process model itself.

In commenting on the way in which mediator self-interest dictates the use of power by the mediator, one respondent noted:

So perliaps mediators start with a predisposition towards settlement but there is also the mediator's own selfinterest supporting this. Even if a mediator doesn't define success by setiling cases, many of the sources of their work do define it that way. If I can say to counsel that I've settled 90 percent of my cases, that is definitely good news to them. So, from a marketing point of view, you have a strong interest in settling cases and you may use your power to achieve that interest if it is the strongest one at the table.

The same mediator added, much later in the conversation while we were discussing an entirely different topic:

You know, 1 was just thinking ... one of the clear interests of the roster [OMMP program] is to clear up backlog and make things move more quickly and cheaply through the court system. Therefore, settlement is the "be-all and end-all" in many ways ... but that creates a strong conflict of interest when it comes to power. If the program has an interest in settling, and you want to be successful in the program, that creates a conflict. The main, perhaps the only criterion for success in mandatory mediation is settlement. So you use power to get there and that is a conflict, even if it satisfies the program's goals and, therefore, your goals. Where do the parties' goals fit in?

In the context of family mediation, another mediator discussed the use of mediation as a way to achieve party goals:

The key issue in mediation is not whether or not we should use power, but rather how we actually do use it ... especially in the context of family mediation, it is unethical to NOT use your power as a mediator. That 
is why they come to you, that is what they want and that is what they nced. To not intervene, to simply manage the process from some distance would lead to, for many divorcing couples, a disastrous result. So I make no apologies for being highly intrusive, but I do it in order to achieve the parties' interests and goals, using power and authority given to me by those same parties from the outset of the process.

Having identified the source of mediator power to lie in the fact that the mediation process belongs to the mediator, another respondent made the following comments relating to the appropriate use of power:

If you use the mediation process and its power fairly and effectively, then it is a meaningful power that can clearly serve the interesis of the parties and even of the program itself. Unfortunately, I don't think that too many mediators use this power for "the good," choosing rather to serve their own interests. Afler all, it's all about who you're working for; the clients, the program or yourself.

\section{And similarly, from another respondent:}

[T] he problem lies in how you choose to use your power. If success is key to you AND you define it in terms of achieving resolution, then youl are likely to feel intense pressure to use your power to aclieve settlement. That is why mediators need to define success completely apart from setlling cases. Because, if your success is defined by achieving the parties' best interests, then you will find yourself using whatever power you have to do that.

Again, this category includes a variety of expressions that suggest that the use of power is determined by an assessment of stakeholder interests. While sometimes, that means power is utilized to achieve the needs of the parties, this assessment of interest may result in the mediator's interests or the program objectives being used to determine the way in which power will be exercised. In the following two categories, we see power being exercised in a manner that ignores divergent interests, selecting, rather, one dominant interest as the goal of utilizing power.

\section{U2: "Mediators use power as a tool to get settlement"}

This grouping is self-evident. Comments in this collection shared the notion that mediators use power primarily, if not entirely, to achieve settlement. While we have already seen articulations of mediators using power to settle cases, the distinction bears repeating. In this category, this use of power seems not to be prefaced on a recognition or assessment of the various interests of the participants, but rather assumes that: (a) the interest to be achieved through mediation is static and independent of the context of each mediation; and (b) that interest is in settling the case.

As will be suggested, the comments repeated here that represent the expressions falling into this category all stem from the premise that mediation's goal is settlement and that this goal either is achieved or should/should not be achieved through the exercise of mediator power. One mediator seemed apologetic about this use of power, stating:

Mediators definitely use their power to get a settlement. I try very hard not to do th is, push towards settlement I mean, because I think that is an abuse of my position and of the system. However, 1 also think that if I 
allowed myself to push harder towards settlement, I would settle way more cases, which would be a very good thing as it would meet my own goals and the goals of the roster. That is what power is used for.

Another mediator was more satisfied with the appropriateness of this use of power:

Mediators must use their power to move parties toward settlement. That is what the power is for, and that is what the mediator is for. It is that simple. That doesn't mean that you have to be aggressive or belligerent. There are many ways of achieving settlement; whatever works, you do it. You are there to get a deal and you have lots of power to make this happen.

\section{And similarly:}

I recognize that we are trained as mediators to focus on the parties' interests. But frankly, sometimes the parties have no idea what is really good for them. The lawyers get in the way; they feed them an idea that they might hope to achieve results in the trial process that are just not feasible. So, I use my power to achieve the only thing that is truly good for the parties; seftlement. Don't get me wrong; it's not that I don't realize settlement is good for me to. It's good for everyone and I use whatever resources I have to get there.

I've heard people say - usually people who don't practice mediation! - that sometimes settlement may not be in the parties' best interest. That is garbage. It is in no one's interest to go through a long drawn out and expensive trial process just so they can say ... say what? That they paid more or got less than they would have if they had settled. Settlement in mediation is always in the best interest of everyone, so l aim for that with every tool in my kit.

While this last comment may be the most extreme expression of the conceptions of power utilization included in this grouping, it is also the most articulate in establishing the goal of settlement as one that supercedes any other interests, perceived or real, held by participants in the mediation process. In the next category, a similar view of the use of power as predetermined rather than flexible and dependent on interests will be illustrated.

\section{U3: "As a mediator, I always grab some power early in the process so that I can show that I will truly be managing the process"}

Certainly, there is some overlap between the object of exercising power that is illustrated in this category and that in the last section. While the previous group of comments focused on the goal of settlement, and these ones target the objective of process management, it questions whether using power to "manage the process" is simply a step in the operation of using power to achieve settlement. In other words, perhaps the implication is that using your mediator power to control the process is how you actually achieve a settlement.

That having been said, a close contextual consideration of the data that emerged identifying this approach to the use of power indicated that while in some cases these two conceptions may be linked, in other example, the act of managing the process was an end in itself, justifying a mediator's use of power to achieve it.

Perhaps the most illustrative articulation of this distinction came in the following comment from one of the respondent mediators: 
My role is to keep control of the process and to move everyone througlt the process smoothly. I am very authoritative in how I do this; for example, I tell everyone that I am going to enforee the ground rules and then I enforce them! The thing is, that is what I bring to the process - power to move through it. I'm not there to worry about what everyone wants out of the mediation, what results they are after and whether those results are realistic ... I'm simply there to make the process move efficienlly and I use my power to achieve this.

Another mediator expressed a similar conception of the use of power by the mediator:

As a mediator, you are extremely powerful in setting the atmosphere, from the minute you answer the phone right through to the last letter you send out to the parties. Everything you do is part of setting a stage, establishing an atmosphere that allows partics to come into the room and get out of it what they want: maybe to settle, maybe something else. You can really set things up so that they feel it is a safe place, a welcome place and a sufliciently controlled environment so that they can feel in control of their situation ... by using your influence to set up this atmosphere, you can have a huge impact on what people can accomplish.

This category of mediator conceptions adds substance to the notion of using power to achieve goals; in this case, process goals. While the various views of power expressed by all respondents in this study recognized power as a means to achieving a certain end, the difference lies in the ways in which the targeted ends are selected. In the case of all three of the categories that we have already considered, mediators accepted their access to power and their utilization of that tool in order to achieve goals, interests that were either flexible and dependent upon the various participants in the process, or interests that were static and independent of the context of a given process. In the final grouping that follows, we see an entirely different approach to the use of mediator power.

\section{U4: “I don't like having power. It's not appropriate. I always redirect it right back to the parties"}

The collection of data that emerged into this grouping suggests a conception of power utilization that $\mathrm{l}$ had not imagined prior to conducting these interviews. Rather than commenting on how power is or should be used by mediators in mediation, the mediators whose expressions fall into this section articulated the view that power should not be used by the mediator at all. Rather, any power in the mediation process rightfully belongs to the parties to be utilized in achieving their respective interests.

As will be discussed in the next section considering the application of power conceptions to categorical theories of mediation, this view of power most closely approaches the philosophy inherent in the transformative model of mediation in proposing an orientation to conflict that empowers parties to transform themselves individually and the relationship between them. ${ }^{48}$

On a deeper level, a more interesting analysis might be whether the power emergent in the mediation process is delegated to the parties by the mediator, or whether it is inherent from the outset in the parties themselves. If the former is true, and the power is somehow directed to the parties as the heading of this section might suggest, then such a process seems to 
evidence a distinct use of power by the mediator, if only to empower the parties to the dispute. The question becomes whether mediators claiming this view of power use are giving their power to disputants, or refusing to accept a transfer of power to themselves from the disputants. From where does the power originate in this framework? The full quotation leading to the heading of this section went as follows:

If partics ask me how they should proceed, I always jog their memories about how we agreed it would go at the beginning. Although $I$ hold a certain power, through knowledge and impressions of the case, I always redirect that power hack to the parties. I guess you could say that I refuse to exercise that power. My sense is that it must be nearly impossible for a lawyer-mediator to redirect power back to the parties. If a clients asks "what should I do? Advise me," the lawyer must always fall back on his trained role to advise as he would do in the normal litigation stream.

By refusing to access power in mediation, from whatever source that power stems, mediators are essentially holding themselves completely separate from the dispute resolution process itself. Query whether such a position is even feasible, given the institutional role of mediators, especially in the court-connected mandatory model currently implemented in Ontario. It seems to me that even a mediator who explicitly refuses to accept power offered by the parties is vested with a certain power of personality, role and position that is difficult to identify or quantify, much less to reject or avoid.

And if such a mediator was able to convince skeptics that she truly exercised no power whatsoever in the process, not even to facilitate the agenda management, then I suppose the next question to answer is, how is such a process different from straight negotiation with an extra person sitting there but adding nothing. Is it possible for anyone in the role of mediator, especially in an institutional court-connected framework, to simply sit back and engage in the process, whatever such engagement would look like, without exercising any power whatsoever?

I suspect this question returns to the definition of power that we each choose. If $\mathrm{I}$, as a mediator, see power as the ability to compel others to behave as I want them to, then it is easier to conceptualize a mediator role that would avoid an exercise of such power. But if I see power as also including the ability to set the agenda or to shape preferences of others, such a power is not only harder to see, but significantly more difficult to refrain from exercising. Why? Because such a power is often latent, exercised solely by either its threat of use or by the perceptions held of it by others, regardless of the accuracy of such perceptions. I may see someone as powerful for a host of reasons of which that person is unaware, and govern myself according to my perception of that power, completely independent of any behaviours exhibited by that person. I would argue that it is virtually impossible to divest oneself of this type of power projected by others. And if anyone is vested of this level of invisible power, surely it would be the mediator with his broad access to a the host of empowering resources.

With these divergent definitions in mind, some mediators commented on wanting to avoid certain concepts of mediator power. For example, one explained: 
Process power is the only power I don't mind having. I am there to help manage the parties through the conflict in terms of what we do next and how we do it, elc. But other than that, I don't want any power at all. I don't want to evaluate options or encourage settlement. That is the best part of my job and what allows me to sleep at night! The power is supposed to remain with the parties throughout, not with me. For me to snatch it ... or even accept it if they offer, is inappropriate. That would make me a participant in the dispute. No thanks.

And similarly, another commented:

Well, I've not thought much about mediator power consciously, I guess. But the way I see it is that I try to avoid all power that I can. I mean, I am there to assist parties with managing their process, but beyond that, I tyy to remain distanced from what is happening with the substance of the dispute. It just is not a place for the mediator to be. I suppose I secretly hope they will find a solution or at least be more realistic at the end, but I don't use power to help get there. So. I guess maybe I have thought about this a bit after all! [laughter]

Certainly, conceptions expressed surrounding the use of power in this grouping were notably less common, and more tentative, than those composing the other categories. There may have been a hesitancy to suggest that a rejection of power in a mandatory scheme that so clearly favours a settlement-driven process, a reality of which a significant number of mediators expressed cognizance. Alternatively, to give the impression that your role was effectively reduced to gathering the participants together and then merely observing them interact may have seemed somewhat limiting to respondents as well. In any event, the comments in this category tended to be less forceful than in the others.

\section{B. Relation of Conceptions of POWer to Categorical. THEORIES OF MEDIATION}

In reviewing the emergent data through several iterations, a noted correlation crystallized between the conceptualizations expressed by mediators surrounding mediator power and the more general conceptions of mediation itself. Simply stated, a significant majority of the mediators who expressed a certain conception of the philosophy of power as a group, tended to group together in expressing a given conception of the use of power. When analyzed, the consistency among the members of this group of mediators extended to include their views of the various components of mediator conceptions of mediation that constituted the theoretical categories set out earlier in this study. How might these conceptions relate to the theoretical categories of mediation proposed above?

\section{The Utilitarian Model of MEdiation}

\section{Conceptions:}

S3: "Mediation is clearly about settling cases!"

G1: "The OMMP encourages early settlement, nothing more and nothing less."

F1: "What I bring is a process consistency that can be relied upon by everyone in the room." 
MI: "It is my process, so I set the rules. I decide what they are and I enforce them as I see fit in order to manage the process more effectively."

Pl: "Power comes from being an expert in the subject of the conflict."

\section{U2: "Mediators use power as a tool to get settlement."}

U3: "As a mediator, I always try to grab some power early in the process so that 1 can show that I will truly be managing the process."

The utilitarian model of mediation resonated strongly with mediator conceptions surrounding power that articulated views of mediator power as an appropriate and effective tool to achieve either substantive or procedural objectives in the process, with or without the knowledge of the participants. This reminds us of the pluralistic view of power focusing on the individual actor consciously exercising power overtly, despite the narrowness of such a view of power has been rejected by Stephen Lukes ${ }^{49}$ and others for its artificial limitation of power to something overt and observable.

While pluralists have focused on a variety of divergent goals of the individual actors being studied, a common thread has been the sense of independence and autonomy of participant actors in dispute resolution processes. Power exists as a fully separate commodity, to be accessed and exercised in isolation by participants in conflict.

In considering the philosophy and use of power as expressed by mediators in this study, we see evidence of the notion of power as self-contained emerge. The mediators whose comments emerged to create this category were able to identify the source of power, be that substantive (that is, legal) knowledge and understanding of the conflict, or the ability to manage the process. Whether the power was substantive or procedural in nature was irrelevant; what linked these comments was the facility with which the respondents were able to identify a clear source of that power and an equally clear "appropriate" usage, in their view. Again, we see a range in this category of mediators who saw power as useful in achieving the objectives of settlement; while others viewed power as enabling the mediator to manage the mediation process effectively. In any event, there emerged a common theme of demonstrating that ability to the other participants in the session and explicitly using that power to achieve the desired ends.

As these categories began to crystallize through the ongoing data analysis, I developed an expectation that the utilitarian category would be populated largely by those mediators with a background in law. This suspicion was based on other work I have undertaken that highlights the way in which the legal model emphasizes sources of power to be used to compel behaviour in others that enhances one's interests. That said, I was interested to note a distinct branch of this category comprised of non-lawyer mediators who approached power in a similar manner but who employed a different currency in exercising it. As I have noted in greater degree in the analysis above, there were a number of mediators whose comments 
in this category emphasized the value of process management techniques, rather than of legal knowledge, in moving parties in a desired direction. While clearly the nature of power to be employed varied among lawyer and non-lawyer-mediators, the approach to and the objectives of this mediator power were strikingly similar.

\section{THE FunCtIONAL/RESPONSIVE MOdEL, OF MEDIATION}

Conceptions:

S2: "Mediation is about helping people look realistically at their options and strategies."

G2: "The program is there to help people understand their interests and their motivations in terms of conflict."

F2: "I tend to start with my standard model, but then go where the situation and dynamics lead me."

M2: "The irony is that I try to maximize the power I can gather early on in the process, but my hope is always that I won't need to use that power."

P3: "To have power is to set the agenda and then to drive it in the direction you want without showing that you have your own goals."

U1: "Used appropriately, power serves the interests of the parties, the process and the program."

The conceptions that framed this theoretical category of mediation were notable in their suggestion of mediation as a process with a significant degree of flexibility and responsiveness to the interests of its participants. This theme is clearly consistent with the conception of power utilization included above, "used appropriately, power serves the interests of the parties, the process and the program." What might seem inconsistent, however, is the inclusion of the $\mathrm{P} 3$ philosophy of power in this category: "To have power is to set the agenda and then to drive it in the direction you want without showing that you have your own goals."

As is noted in the analysis accompanying the P3 conception above, I connect the comments in this grouping directly with the theoretical view of power that includes in its definition the capacity to shape the preferences and interests of a party perceived as having opposing interests and preferences, so that the party is unaware of their true interests and thereby precludes the emergence of any conflict based on a clash of those interests. The aspect of this conception that properly locates it in this category is the implication that power is strongly dependent on advancing interests and, as a corollary, shaping or modifying the interests of others that could be perceived as being divergent from one's own.

All of the conceptions included in this category of mediation focus on interests as the chief motivator in determining mediator approaches and views. Mediators in this category are 
highly cognizant of interests, be they the interests of the mediators themselves or any combination of participants or the institutional program behind the process. These mediators recognize that mediation process and outcomes need to address interests in order to work effectively and that these interests are changing and interdependent.

This is clearly contrasted with the utilitarian model that identifies only one interest and designs an approach that works to achieve that universal interest without adopting a contextual analysis of potentially competing, and compelling, alternative interests.

\section{THE RELATIONAI. MODEL OF MEDIATION}

Conceptions:

S1: "Mediation is successful if the mediator sets an example of how to handle conflict."

G3: "The OMMP, while not intended to empower people, does give parties a chance to get their voices back and to use them."

F3: "We all study this standard model, but you know what? You use what works in a given situation."

M3: "I negotiate everything. I ask for input and then we all decide together on the best approaches to the matters as they arise."

P2: "Power isn't about knowing the law; it's from managing the process effectively."

U4: "I don't like having power. It's not appropriate. I always redirect it right back to the parties."

Finally, in the relational model of mediation, we continue to approach the transformative end of the mediation spectrum without actually arriving there. We see repeated themes across several categories of conceptions that note the centrality and interdependence of relationships in the mediation process, but we do not quite see the philosophical rejection of the "settlement story" that characterizes the transformative model of mediation. We do, however, see a highly contextual and consensual process that is party-driven and responsive to the needs of participants.

It strikes me that the emergent conceptions surrounding power philosophy and utilization connect well with this theoretical model. In the P2 analysis included above, we see comments that talk about power as ensuring parties trust the process and have confidence in the mediator's ability to manage it; or identify power as coming from the capacity of a mediator to "listen and hear" and demonstrate she is listening and hearing. This category recognizes the importance to an effective mediation process of a mediator who observes parties and their relationships both to one another and to the conflict. In particular, the mediator conceived of by this category is very reluctant to empower himself or be empowered by the parties, as 
that would potentially place him at the table as a participant rather than as a party meant to assist the disputants in achieving their own identified needs and interests.

These mediators are open to the possibility of models and approaches that extend outside the "box" of the mediation training that they received and are likely to try to import successful approaches used in one framework of mediation (voluntary family mediation) to another model (mandatory civil mediation), with a recognition that such an attempt is often unsuccessful. From the perspective of power, these mediators see power as one more element of the conflict dynamics, to be addressed by the parties while the mediator herself is occupied with creating an environment that allows for an improvement in the relationships or settlement, depending on the goals of those parties.

\section{CONCLUSIONS}

As with every other aspect of mediation, mediator power invites divergent views from the mediators practising in this field. Some see it as a tool to be maximized and used to achieve a specific end. Others see power as a function of the competing interests at the table, to be utilized in a flexible way to achieve varying objectives. Finally, still other mediators conceive of mediator power as something to be shunned, something that more appropriately rests with the disputant parties and not with the facilitator of the process. Having considered the three categorical theories of mediation that emerged from the data collected in this study, the relationship to mediation conceptions of power is quite striking. Clearly, the interconnectedness of these conceptions creates three compelling categories or models of mediation, as expressed through interviews with the subject mediators in this study.

Acknowledged from the outset of my work, the scope and application of this study is clearly exploratory. There remains significant work to be done, using these findings as a starting point. As a suggestion, this study should be expanded using a larger sample of respondents and with the added stage of asking those respondents for their reaction to the three proposed categories of mediator perceptions.

But, even in their limitations, we must ask about the implications of these findings for those concerned with civil justice models and trends in Canada. Certainly in Ontario, civil case management is poised to spread across the province, current reforms in Toronto notwithstanding. As results indicate the settlement of more cases earlier in the process, the broader application of this program is likely. It is of interest, however, to have a better idea of how those cases are being resolved. The "how" of those cases settled through mediation should be worth considering, as we can identify a group of rostered mediators who demonstrate a strong commitment to settling all cases that they mediate under the auspices of the OMMP. Working within a program explicitly focused on increasing settlement, it questions whether these mediators could help but link their own rates of settlement to gaining favour with the program administrators and guaranteeing them a continued income stream as professionals.

While certainly the early settlement of litigated actions often aligns with the parties' best interests, arguably there are cases, and parties, who are better served otherwise. Rather, while scholars seem unable to agree on the population of this group, there is some consensus that 
a group of cases exist that require the full treatment of the litigation process in order to achieve just results, whether that be for reasons of personal entitlement or larger social good and progress. Similarly, there are litigants whose relationship dynamics are such that mediation is prone to propogate an unhealthy power imbalance without the theoretical safeguards of litigation. And, as noted above, even in those cases best suited for early settlement, mediation may fall at a stage in the progress of that case, usually before discovery, where it is simply too early to have all the information necessary to settle. Until we have a better idea of what is happening in these mediation sessions, we cannot begin to expound on their "success." And, until we have a better idea of the way in which mediators think about mediation, and how those thoughts impact on mediator behaviour, we are far from making any conclusions about mandatory mediation and its success other than as a blunt tool of case settlement.

Also noteworthy by its absence in the emergent data is any population of the respondent mediators to claim the model or components of transformative mediation as their guiding philosophy. As noted, some mediators touched on some of the relational aspects of this model, but none of the mediators suggested the most appropriate use of their power to be, for example, the empowerment of the disputants to repair their relationship or transform their view of conflict. What does it tell us that this end of the spectrum of mediation models so widely adopted in other settings is simply non-existent in this population of mediators? Surely, the way in which mediators understand and profess to utilize their own extensive power has significant potential for changing the shape of the mediation process and its potential outcomes. I would have expected that at least some of those interviewed would have expressed a view of mediation as it relates to conflict in keeping with the widely known and practiced principles of the transformative model. That this important model of mediation was completely without representation among the participants in this study should give us great pause and further motivation to understand exactly what is happening in this process.

\section{Discussion: Power in Mediation}

Mandatory mediation is notable in its combination of two key ingredients: (1) professional mediators with a self-interest in achieving high rates of settlement so as to continue in their rostered position; and (2) a process that gives those mediators access to greater power than any of the other participants, power to direct the mediation, either consciously or unconsciously, in a way that will achieve those self-interests referred to.

As a field, both scholars and practitioners have linked the "magic" of mediation to the impartial and neutral third parties who act as mere process facilitators, avoiding the crossover into advocacy, substantive analysis or the creation or promotion of specific solutions. As noted, this idealization was expressed by many subjects in this study, most of whom claimed to achieve these objectives in practice. However, one of the key findings of the emergent data points to a significant gap between the theory of practice and the practice itself. When this gap becomes especially critical is in the context of mediator power. While valuable work has concentrated on notions of participant power and power imbalances, little has been done to empirically address mediator conceptions of their own power. 
According to at least one theorist, ${ }^{50}$ a chief concern with mediation is its core assumption of human beings as autonomous, complete agents of their own destiny. By treating individuals as actors who can ignore values, norms and social forces in constructing processes outside of cultural or societal expectations, we miss the reality of individuals as intimately connected to structures that determine their interests and their capacities to act accordingly. Birkhoff argues that historical forces (the economy, racism, sexism) doom individuals as pawns in informal processes that do not protect their interests. Part of the foundation of this study is a recognition that power is exercised in non-transparent ways that have ramifications for the capacity of each person who encounters that power to act autonomously.

As conflict theorists assessing power and its role, it also raises the question of the interrelationship between power and informal conflict resolution. While we each have varying degrees of the capacity to act in our own interests, it is clear that powerful social forces work to shape the frameworks within which each of us acts. A comprehensive theory of power and conflict would be incomplete if it did not integrate both micro and macro perspectives on individual action.

Rather than handing passive disputants a resolution to their conflict, mediation claims to place ownership of that conflict and its solution squarely in the hands of the disputants themselves. What that equation ignores, however, is the distinct interests that the mediator may bring to the process, interests that may be created and fuelled by the very model within which the mediation operates. Recognizing the potential for such mediator self-interest begs the question; is the mediator a truly neutral and impartial agenda manager? Or, does that mediator harness substantial power at the mediation table, power used to manipulate disputants through process management and interventions towards an outcome that corresponds with the mediator's settlement-orientation and perceptions of fairness? At some point, we need to consider as a scholarly community whether this model of informal conflict resolution can ever be appropriate, given the nature mediator power.

Perhaps it is the characteristics of mandatory mediation schemes, at least of the one in Ontario, that create a situation where mediator power becomes critical to the process. In a mediation model that encourages (rewards?) in mediators a distinct interest in settlement, potentially in direct conflict with the interests of the disputants, the addition of power to satisfy that orientation becomes significant. Perhaps the existence of mediator power in a mediation model that is not based on a select roster of mediators and that is not centred on an objective of case management and settlement, is not as relevant in the process equation. That inquiry remains for another day.

Of interest here is the impact of that power on a rostered, mandatory model where increasing the rate of settlement is an explicit objective of the system, an objective that is tracked and scrutinized following the completion of each mediation session. The emergent data of this study evidences a strong population of mediators, almost exclusively legally 
trained, who view settlement not only as the leading objective of the OMMP itself, but also as their own personal goal, irrespective of any unique characteristics of a given dispute or interests of its disputants.

From the outset of this work, I was curious as to the extent to which this objective transformed into pressure felt by the mediators to settle on any grounds, simply to curry perceived or actual favour with the program by achieving a high settlement rate. By managing process, a seemingly benign administrative function, I suggest that significant choices are made by the mediator that alter the way that parties perceive of potential outcomes of the process. As outcome potential perceptions are modified, parties naturally shift their own preferences to align with the modified outcomes perceived to be achievable. But what does this process say about mediator neutrality?

The concept of mediator neutrality has its roots in legal anthropology from the mid-20th century. In 1955, one labour mediation researcher noted her findings that while labour mediators strongly disagreed with her suggestion that neuirality was mythical, observation of their practices determined that they did in fact "[feed] determinants into the flow of bargaining interaction which influenced and shape[d] the outcome." 1 I Similarly, in his studies of cross-cultural aspects of mediation and negotiation completed in 1977 and 1979, social anthropologist Paul Gulliver concluded that mediators regularly exercise influence, either passively or actively, and that such influence serves to assist in reaching an outcome palatable to the mediator, corresponding to his own ideas and interests. ${ }^{52}$

In their study of divorce mediation, Greatbach and Dingwall distinguish between the routine agenda management that occurs in any orchestrated meeting and what they claim to be the selective facilitation that a mediator employs which, while formally neutral on its face, is in fact directed toward influencing outcomes. This, according to the authors, provides a "scope for mediators to encourage some outcomes and to resist others while continuing to present themselves as neutral." "S3 They claim this use of power is legitimate in the context of power imbalanced divorce mediations, stating that "[m]ediator influence becomes a problem only when formal and substantive neutrality are confused so that the pressure becomes invisible or when the choice of goals remains a purely personal matter rather than one for which the practitioner may be socially accountable." 54

When the notion of the mediator "levelling the playing field" between imbalanced parties was discussed in the interviews of this study, many of the respondents claimed this practice as a legitimate - in fact necessary - role of the mediator, an approach that has been supported by theory in the field. ${ }^{\text {ss }}$ Others clearly rejected this approach, noting it was outside

Ann Douglas, "What Can Research tell us About Mediation?" (1955) 6 Lab. L. J. 545 at 557.

P.H. Gulliver, "On Mediators" in Lan Hammetl, ed., Social Anthropology and Lav (London: Academic Press, 1977) 15; P.H. Gulliver, Dispules and Negotiations: A Cross-Cultural Perspective (New York: Academic Press, 1979).

33 Greatbach \& Dingwall, supra nole 5 at 638.

s4 $\quad$ bid. at 639 .

ss See generally, Rifken, Millen \& Cobb, supra note 4; Michael Coyle, "Defending the Weak and Fighting Unfaimess: Can Mediators Respond to the Challenge?" (1998) 36 Osgoode Hall L.J. 625. 
of the scope of the mediator's role to adjust or balance party dynamics as such behaviour would evidence a loss of neutrality and impartiality on behalf of the mediator.

In a related, more recent study of mediator behaviour, Jacobs and Aakhus identified three models that mediators employ to interpret conflict situations and determine the most appropriate way to move forward. ${ }^{56}$ Having observed and analyzed 41 mediation sessions, these researchers concluded that mediators select a particular framework of activity in the mediation sessions that has significant impact on the substance, direction and outcomes of that mediation session. For example, they note that arguments are discouraged and deflected in two of the three models, the bargaining model and the therapy model. Specifically, in the bargaining model, that the authors deem to be the most commonly adopted by mediators,

mediators tend to interpret arguments as altempts to resist proposals rather than as attempts to reason together.

Rather than finding in the back and forth of argument and counterargument an opportunity for resolving disagreement, mediators usually see evidence of entrenched resistance and an unwillingness to accommodate the other party. ${ }^{37}$

These researchers concluded that the outcomes achieved using this model can be traced directly to this deflection of arguments. By framing these three models in the context of mediator competency, claiming that every mediator should be able to choose and apply the appropriate model of during a particular mediation, Jacobs and Aakhus missed a golden opportunity to discuss the implications this research has for furthering our understanding of mediator power. Rather than applauding this manipulation of parties as necessary skills held by the competent mediator, a far more interesting analysis would have followed had they considered the appropriateness, from a power analysis perspective, of mediators behaving in this manner.

When viewing power from the mediator's perspective, we encounter the argument that this would only be actual power if the mediator used her role as a process manager to achieve/maintain her own interests or preferences, distinct from the interests or preferences of the parties themselves. I disagree. There need not be a set of discrete preferences in order to hold power. And even if such a set was required, I would argue that within the context of court-annexed or "mandatory" mediation, the very nature of that process provides sufficient self-interests and preferences for the mediator, separate from those of the disputants, to ground an exercise of power in this form.

As such, when power is viewed in a framework of setting a decision-making agenda to keep certain issues "off the table," or in a framework of shaping interests and preferences of a potential opponent so as to align those interests with one's own, it strikes me that a mediator, especially one operating within a mandatory mediation scheme, is in the best position to exercise these forms of power. By definition, the mediator administers and controls the process, carrying the institutional legitimacy of having been assigned by the court. I suggest that the explicit focus of mandatory mediation in Ontario on achieving significant rates of settlement provides the mediator with some central self-interests that will 
guide, if not govern, her use of the power that is available to her, in order to satisfy these interests. This, despite the potential inconsistency between her interests and those of the disputants whom she is there to assist. A closer look at mandatory mediation in Ontario may serve to explain the development of a strong settlement-orientation in its rostered mediators.

Where do we go from here? As noted above, an expanded version of this study is in order. We need to investigate some of the connections between mediator orientations and program models more fully before the results of this work can be fully understood. It would also be helpful to enrich the dimensionality of the qualitative methodology employed here with the addition of data generated from both the observation of mediators at work and the views of those mediators who are given the categorical theories of mediation proposed here as a focus of reflection.

While this study scratches the surface of an entire research agenda on the mediation process, it strives to begin the task of filling gaps in our scholarly understanding of the mediation process. Rather than manipulating endless variables to test input-output conclusions that have been advanced with a view towards enhancing participant satisfaction, this seeks to begin to understand what happens in mediation by asking the mediators themselves. What we are beginning to see is that there is a tangible settlement-orientation among those mediating in our mandatory scheme, and that these mediators are quite prepared to view and to use their own power as a tool for satisfying that orientation. While this approach may well align with our own objectives for mediation, and the stated objectives of the program architects in the civil case context, we need to achieve a level of consciousness about this reality rather than falling back on the, perhaps, misplaced idea that mediation is to be about neutral and impartial third parties whose only interest in a case is to facilitate better communication among the disputants. When we adopt, in Ontario, a model code of mediator conduct that contains assurances of impartial mediators and party selfdetermination, perhaps we might begin to view the orientation of mandatory mediators with a renewed interest. 